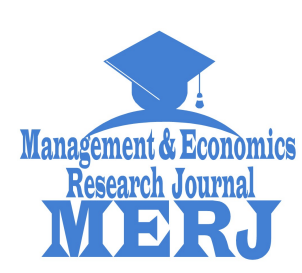

\section{و}

Management \& Economics Research Journal ISSN 2710-8856 (Online)

ISSN 2676-184X (Print)

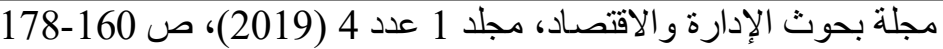

Management \& Economics Research Journal, Vol. 1 No. 4 (2019), pp. 160-178

do) https://doi.org/10.48100/merj.v1i4.67

Check for updates

\title{
أثر المناخ التنظيمي على السلولك الإبداعي: دراسة تحليلية لآراء عينة من الموظقين بمدبغة الهضاب العليا بالجلفة
}

مصطفى بن عودة 1 •، صبرينة حمياني 2

1 دكتور اه، أستاذ محاضر أ، جامعة زيان عاشتور بالجلفة (الجزائر )

$\triangle$ benaoudamoustapha@gmail.com

2 دكتور اه، أستاذة مؤقتة، جامعة زيان عاشور بالجلفة (الجزائر)

$\triangle$ sabrinahamiani@gmail.com

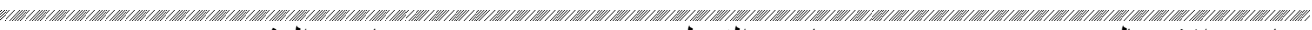

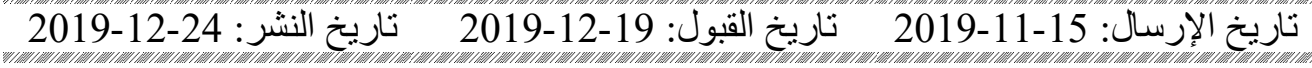

هدفت هذه الدر اسـة إلى تقييم المناخ التنظيمي السائد، ومسـتوى السـلوك الإبـداعي في مدبغــة

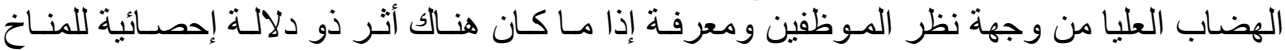

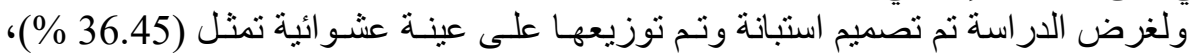

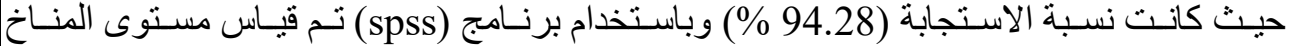

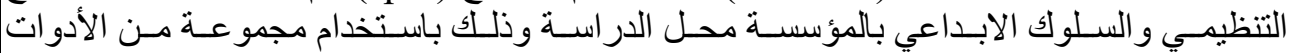

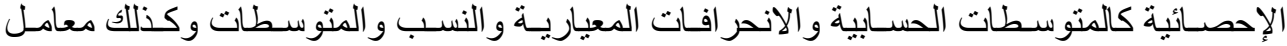
الارتباط ومعامل التحديد.

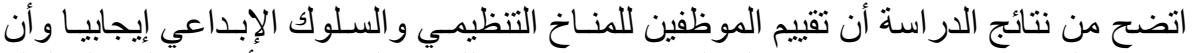

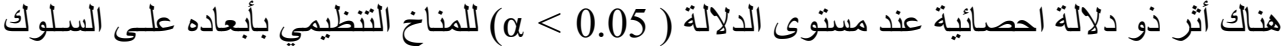

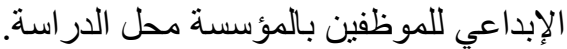

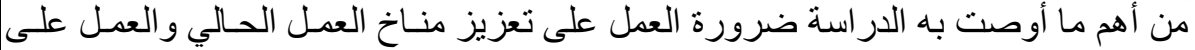

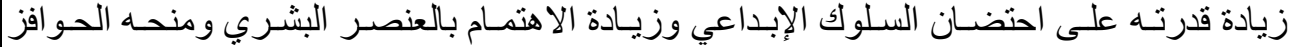
المناسبة. الكلمات المفتاحية: المناخ التنظيمي، السلوك الإبداعي، مدبغة الهضاب العليا. تصنيف جال : M19.

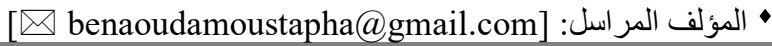

كلية العلوم الاقتصادية، التجارية وعلوم التسيير، جامعة زيان عاشور بالجلفة، ص.ب: الاقتصادية التجارية وعلوم الجسيير، (الجزائر). 
مصطفى بن عودة، صبرينة أثزر المناخ التنظيمي على السلوك الإبداعي: دراسة الجلفة ميدانية على مدبغة

\section{1. مقدمة}

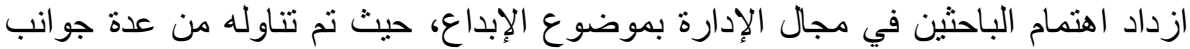

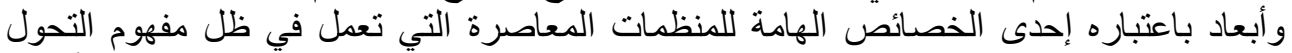

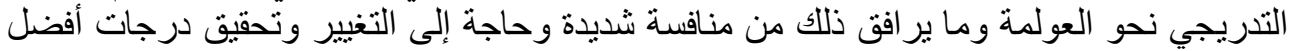

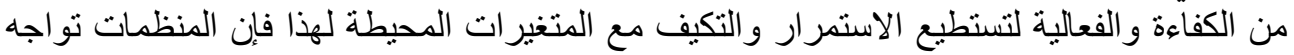

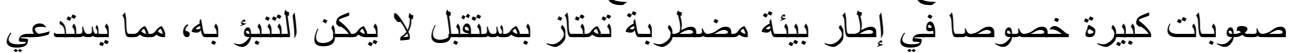

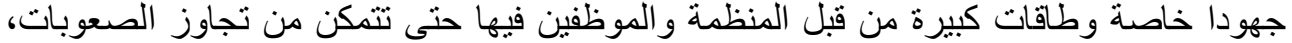

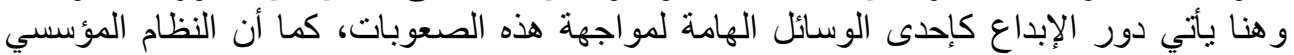

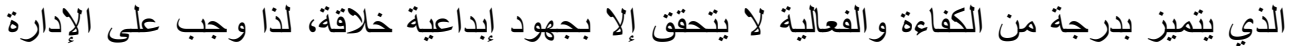

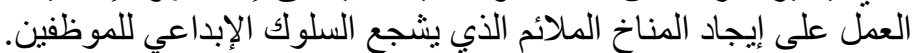

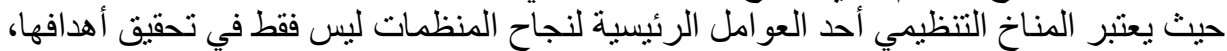

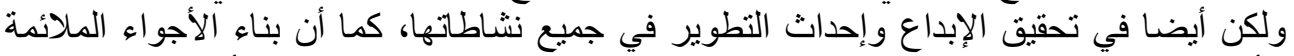

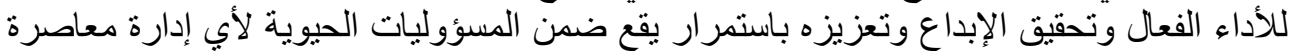

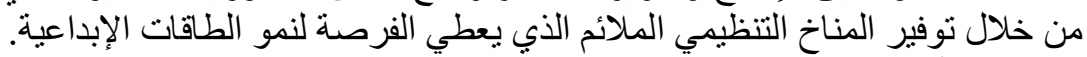
1.1

لما كان المناخ التنظيمي يعكس خصائص البيئة الداخلية التي تؤثر على سلوك الأفر اد وكان

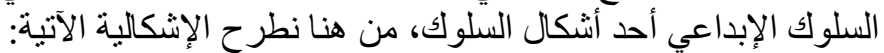

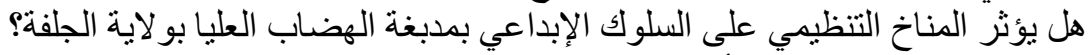

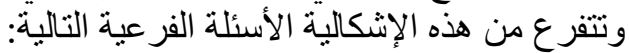

- - هل يؤثر الهيكل التظيمي على السلوك الإبداعي بمدبغة الهضاب العليا بو لاية الجلفة ؟

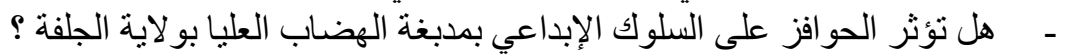

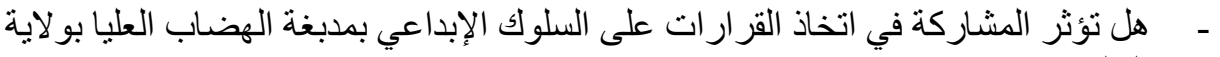
الجلفة ؟

- - هل تؤثر التكنولوجيا على السلوك الإبداعي بمدبغة الهضاب العليا بو لاية الجلفة ؟

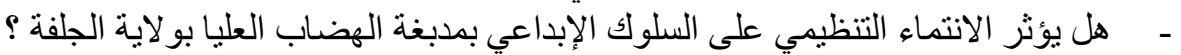
2.1

و انطلاقا من المشكلة الرئيسية والأسئلة الفر عية السابقة، تم وضع فرضية رئيسية هي: "يوجد أثر ذو دلالة إحصائية للمناخ التظظيمي على السلوك الإبداعي بمدبغة الهضياب العليا بو لاية الجلفة ".

و تثفرع من هذه الفرضية الرئيسية الفرضيات الفرعية التالية:

- يوجد أثز ذو دلالة إحصائية للهيكل التظيمي على السلوك الإبداعي بمدبغة الهضياب العليا بو لاية الجلفة ".

- "يوجد أثز ذو دلالة إحصائية للحوافز على السلوك الإبداعي بمدبغة الهضاب العليا بولاية الجلفة ". - "يوجد أثر ذو دلالة إحصائية للمشاركة في اتخاذ القرارات على السلوك الإبداعي بمدبغة

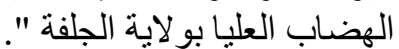
- - مجوجد أثر ذو دلالة إحصائية للتكنولوجيا على السلوك الإبداعي بمدبغة الهضاب العليا بولاية الجلفة ". 


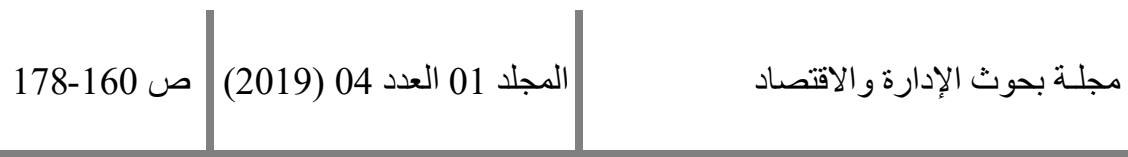

- - ليوجد أثر ذو دلالة إحصائية للانتماء التنظيمي على السلوك الإبداعي بمدبغة الهضاب العليا بو لاية الجلفة ". 3.1

سنحاول من خلال هذه الدر اسة إلى تحقيق الأهداف الآتية:

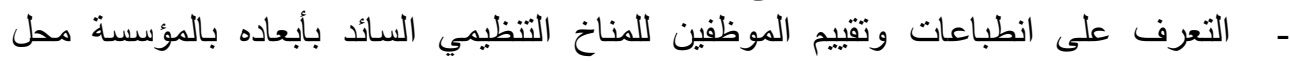
الدر استة. التعرف على مستوى السلوك الإبداعي لدى الموظفين بالمؤسسة محل الدر اسة.

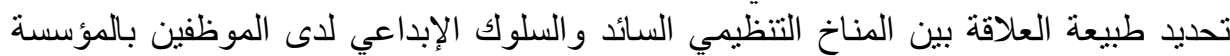
محل الدراسة.

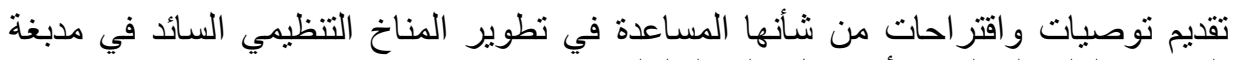
الهضاب العليا، لما له من أثر فئر فعال على التى السلوك الإبداعي فيها. 4.1

تكمن أهمية هذه الدراسة في التعرف على طبية الهية المناخ التنظيمي السائد بأبعاده المختلفة من

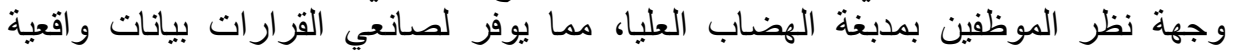
تساعدهم في تبني سياسات وإجراءات من شأنها تعزيز الأبعاد الإيجابية وتصويب الإيب الأبعاد

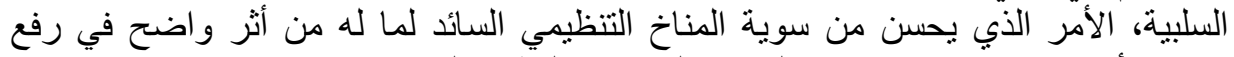

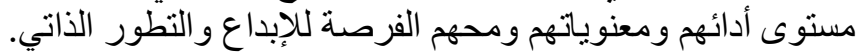

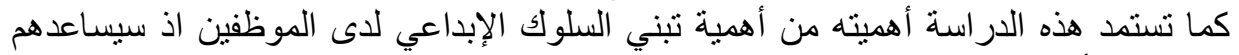
على تبني أساليب عمل جديدة تختلف عن نمطية العمل التقليدية مما يسهم في حل مشكلات

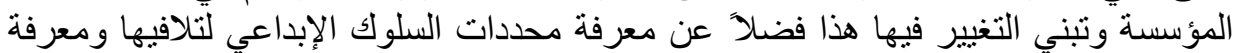

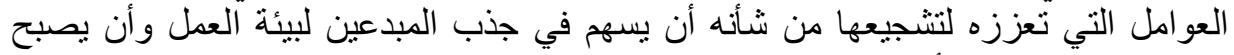
السلوك الإبداعي قيمة أساسية فيها.

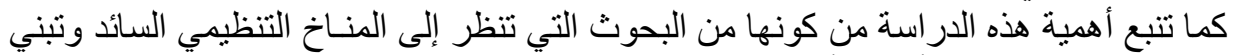

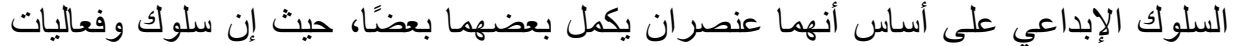
العمل بالنسبة للَعاملين تعتمد بشكل رئيس على درجة الإبداع الدعم والتشجيع التي يوفر ها المناخ التنظيمي لهم. كما ستسهم هذه الدراسة عن طريق التوصيات التي ستقدمها في تعزيز السلوك الإبداعي لدى في الموظفين لما له من أثر فعال في تحقيق الفعالية التنظيمية. 5.1

من أجل الإحاطة بإثكالية الدر اسة وفهم جوانبه المختلفة حددنا مجال در استنا بما يلي:

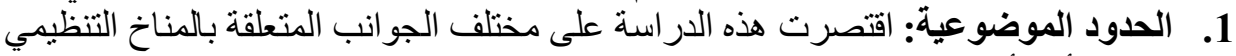
ومدى تأثنير أبعاده على السلوك التود الابداعي.

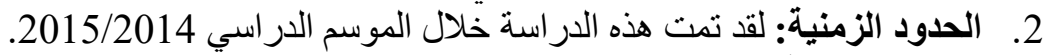
3. الحدود المكانية: لقد نم إسقاط الجانب النظري لهذه الدراسة على مدبغة الهضاب العليا بو لاية الجلفة. 4. الحدود البشرية: قمنا بتوزيع الاستبانة على عينة من الموظفين في مدبغة الهضاب العليا بو لاية الجلفة.

\section{1} قمنا باستخدام المنهج الوصفي التحليلي من خلامل مر اجعة الكتب و الدوريات والأطروحات

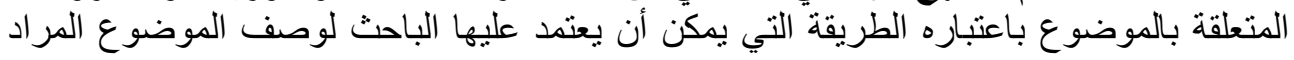




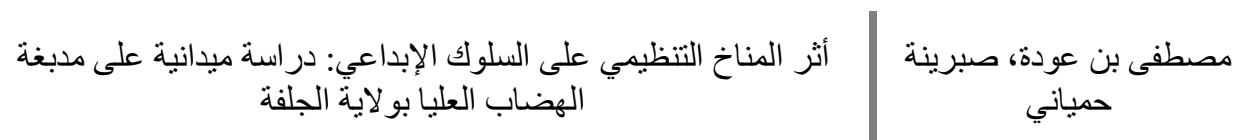

دراسته من خلال منهجية علمية صحيحة وتصوير النتائج التي يثم الوصول إليها على أثنكال رقيّة الإنة

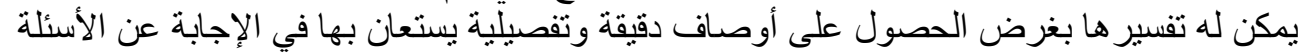

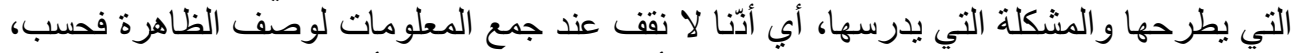

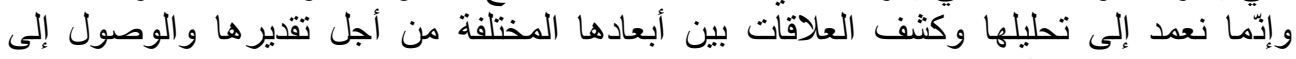
استنتاجات تساعد على فهمها. شكل رقم 1: أنموذج البحث

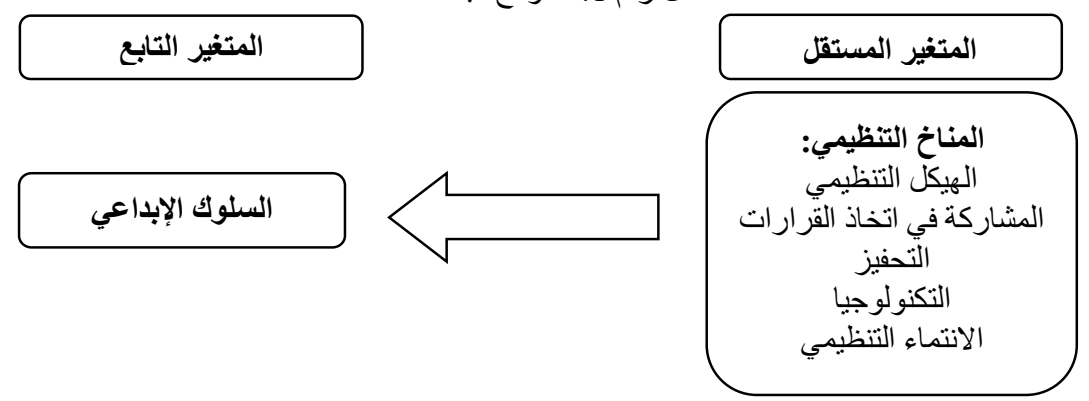

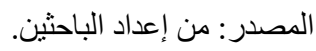

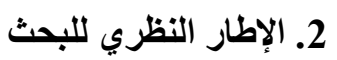

سنتطرق فيما يلي لبعض المفاهيم التي تخص متغير ات الدر اسة: 1.2 التأصيل النظري للمناخ التنظيمي لبعزي

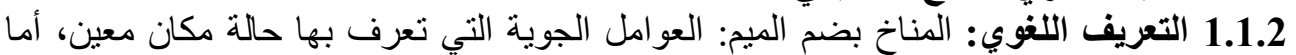

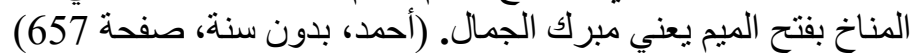

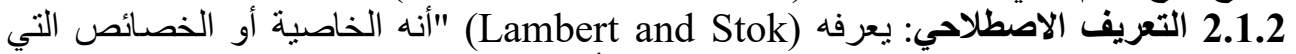

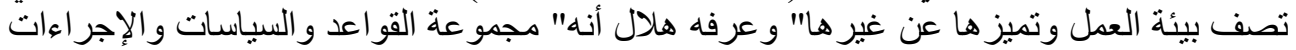

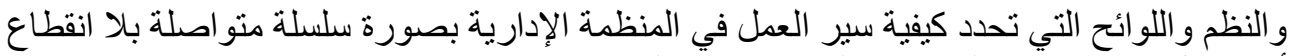
أو تعطيل"، حيث ركز التعريف على خصائص النص المنظمة.

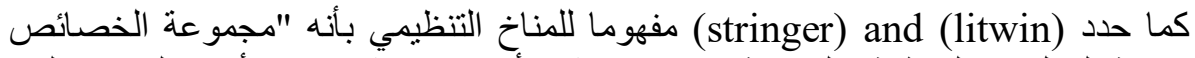

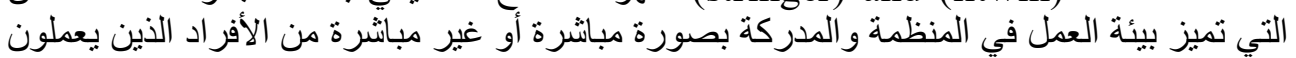

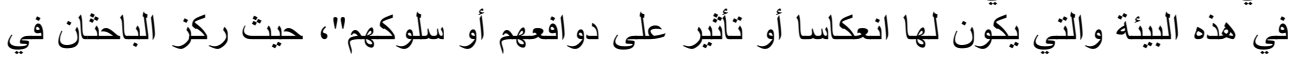

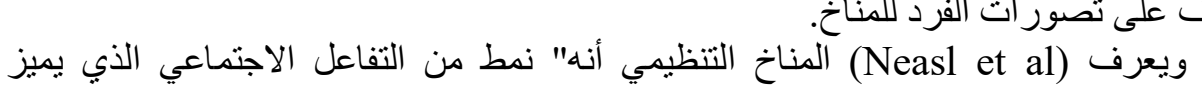

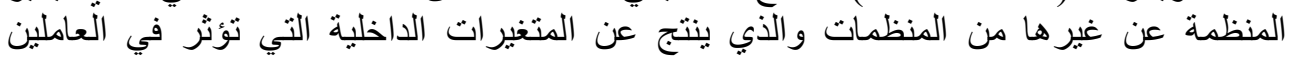

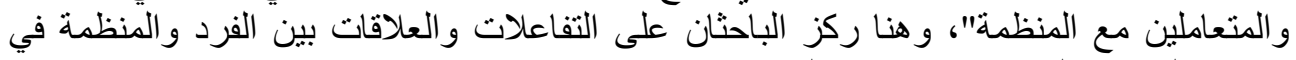

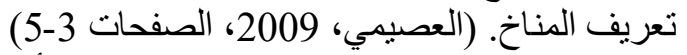

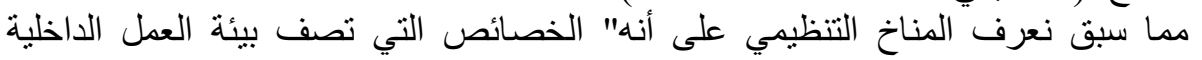

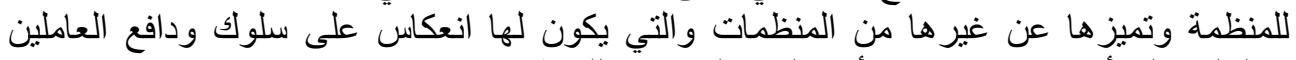

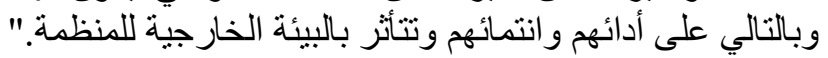




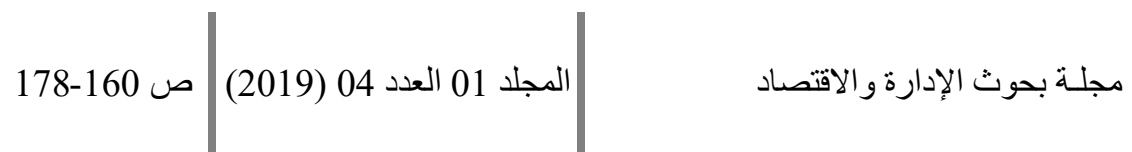

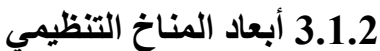 \\ تتمثل أبعاد المناخ التنظيمي في الأبعاد الآتية:}

ـ الهيكل التظظيمي

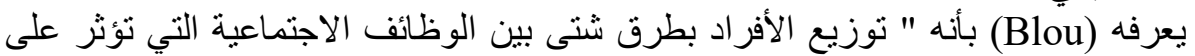

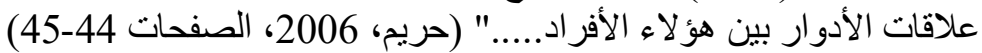

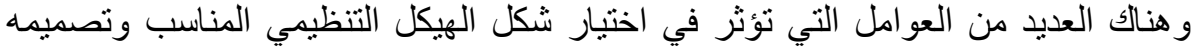

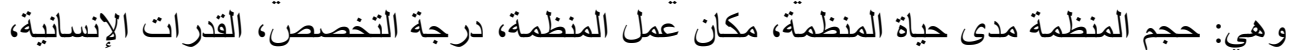

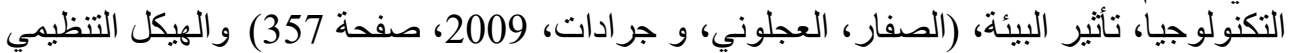

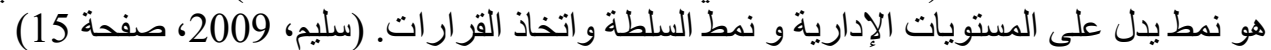

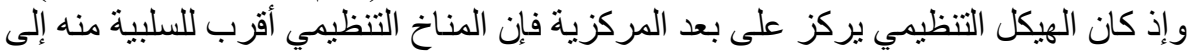

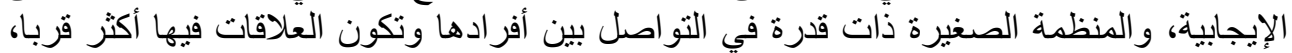

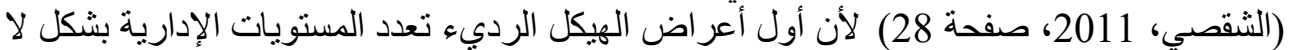

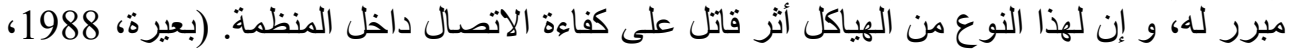

صفحة 71) الهان أن

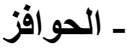

تعود كلمة حو افز إلى مادة حفز في اللغة و هي بمعنى دفعه من خلفه وتثنير لفظة الحو افز في

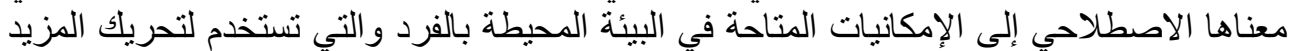

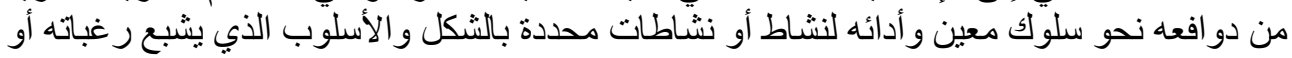

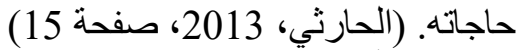
ـ المشاركة في اتخاذ القرارات:

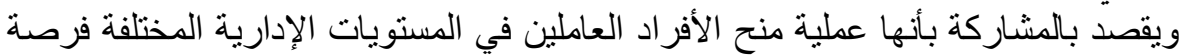

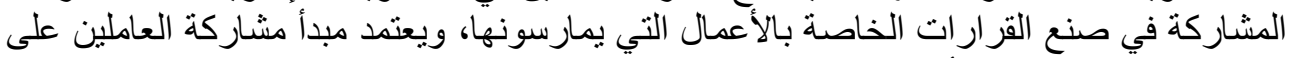

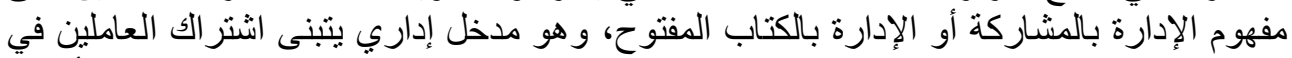

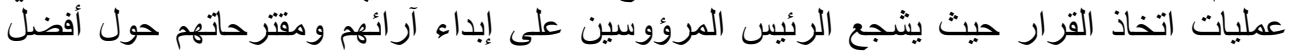
الطرق لأداء العمل بحيث لا يكون على مستويات الإدارة العليا. (علي و علئ، آلئ 2014، الصفحات

(506-505

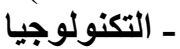

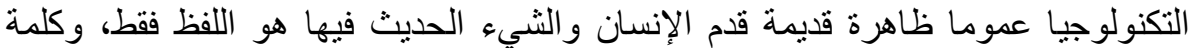

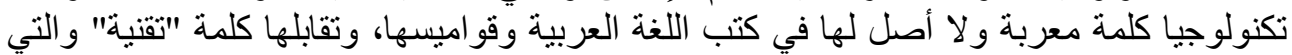

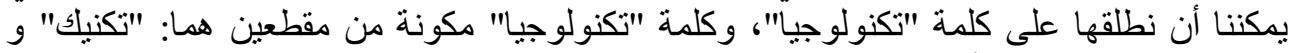

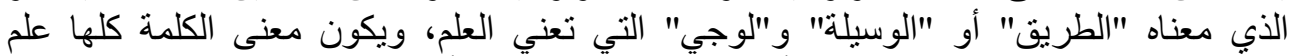

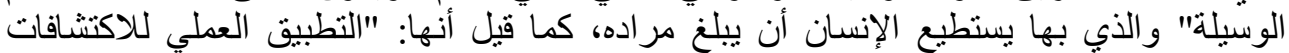

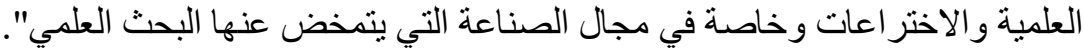

ـ الانتماء التنظيمي

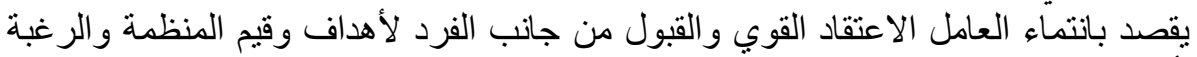

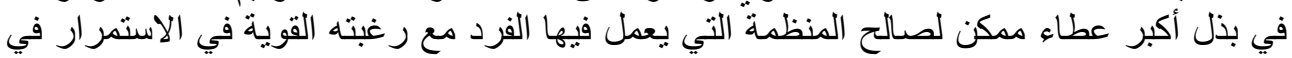

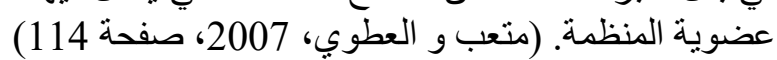

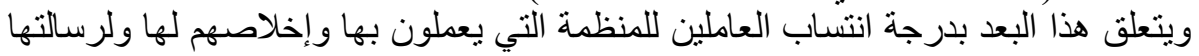

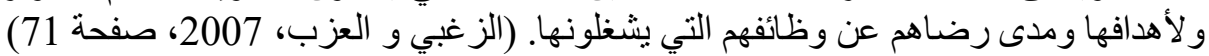
2.2 التأصيل النظري والفكري للسلوك الإبداعي: 


\subsection{2 تعريف الإبداع الإعاع}

الإبداع هو " الإتيان بما هو جديد سواء كان سلعة أو خدمة أو فكرة ويكون الإبداع فردي أو

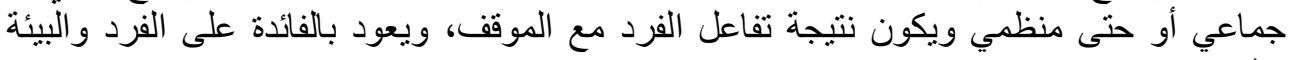

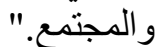

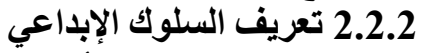
يرى (العزاوي) أن السلوك الإبديداعي يكمن في " كيفية تفكير الفرد بعيدا عن السياقات

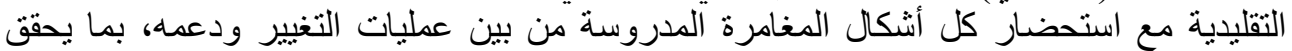

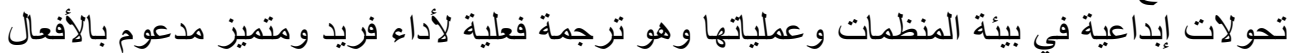

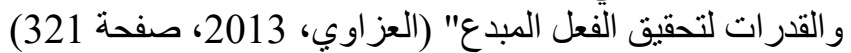
ويذكر (يوسف الزيادين) أن السلوك الإبداعي يشمل "جميع الأفعال الفردية أو الجماعية

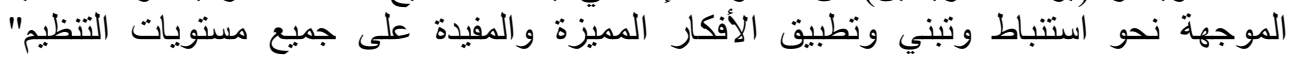

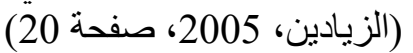
كما عرفته (أميمة الدهان) أنه "السلوك الذي يتفرد به الشخص عندما يو اجه مواقف يتأثز

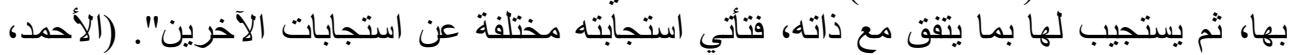

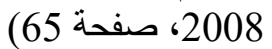
ومنه نستتج أن السلوك الابداعي "يتمنل في كافة السلوكات الفردية والجماعية المرغوبة

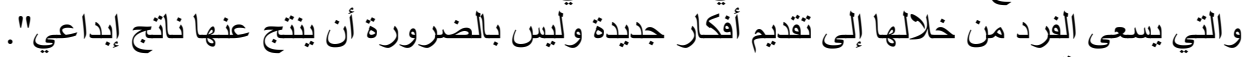

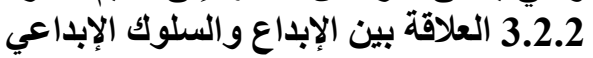

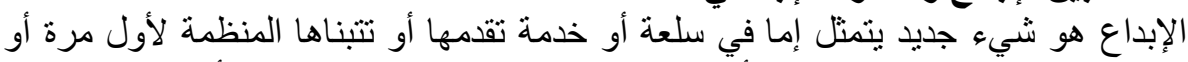

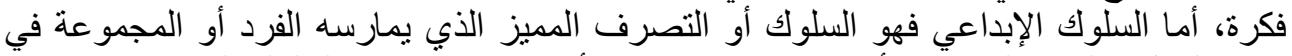

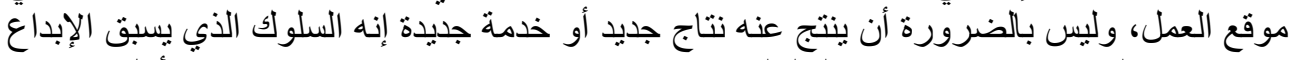

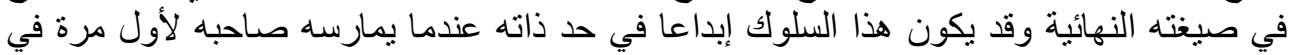

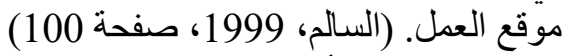

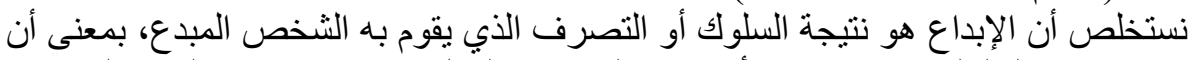
الإبداع نتيجة بينما السلوك الإبداعي هو أداة ووسيلة تسبق العمل الإبداعي وتقود إليه، الإعل (الزيادين،

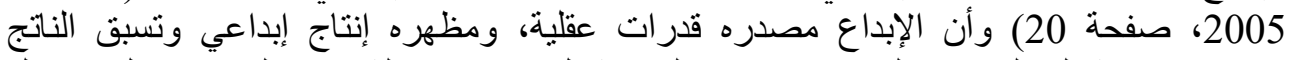

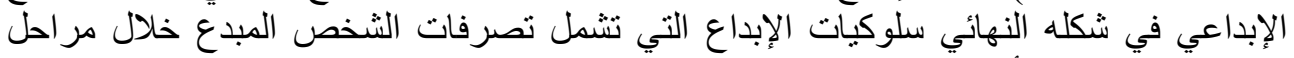

أثـار (Ettilie \& keefe,1982) إلى أن أهم الأبعاد التي تعمل على تنمية وتطوير السلوك

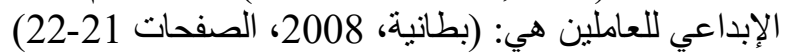

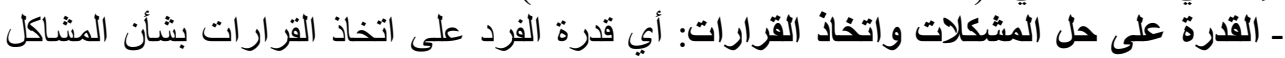
التي يمر بها في الوقت المناسب بالإضافة إلى إمكانية التعرف على المشكلات والبكات والبحث عن الحلّول الابتكارية. ـ القدرة على التغيير: وتعبر عن منابعة الفرد للأفكار الجديدة وتطوير ها والرغبة في الدخول إلى

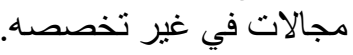
- روح المجازفةة: وهي رغيرة فئة الفرد في القيام بأعمال ذات مخاطرة عالية وتخصص الأموال لذلك،

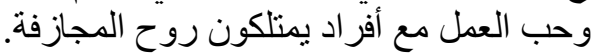

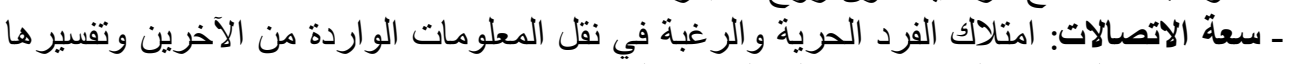
وتطوير العلاقات الشخصية مع العاملين في المنظمة. 
المجلد 01 العدد 04 (2019) ص 160-178 ص

ـ تشجيع الإبداع: ويعبر عن حب التعرف على الأفكار الجديدة ونقدها وتشجيع المقترحات التي

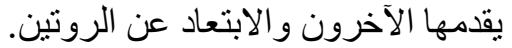

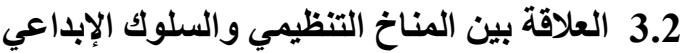

يشكل المناخ التنظيمي بأبعاده مقومات التوات السلّوك الإبداعي بالمنظمة حيث يتأثر هذا الأخير بأبعاد المناخ التنظيمي: التئي

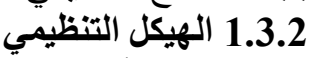

تعتبر أهية الهيكل التنظيمي من أبرز التقاط التي تناولتها الدراسات بسبب تأثثر ها المباشر

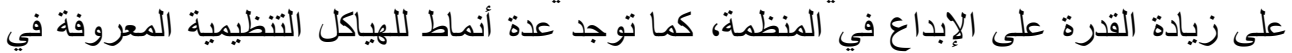

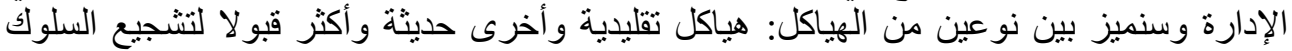

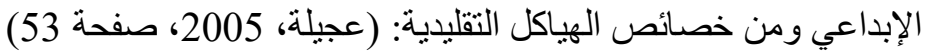

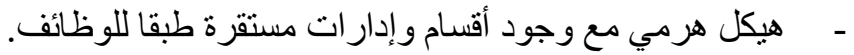
- - ملبة الاتصالات العمودية على الأفقية.

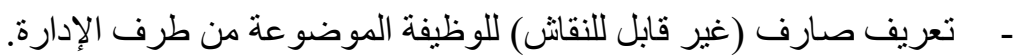
بينما تمتاز الهياكل الحديثة بالخصائص التالية النية: - - هيكل أفقي منبسط مع وجود جماعات وفرق الأن عمل مؤقتة طبقا لمشرو عات محددة.

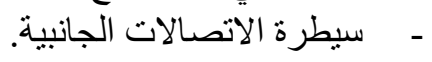

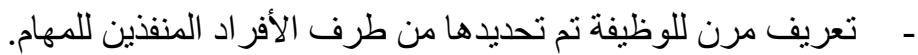

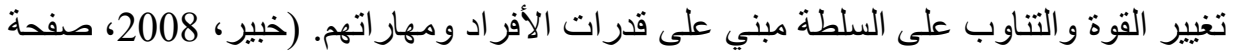

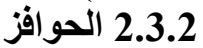

تعتبر الحوافز إحدى الوسائل التي تهدف إلى حث الأفر اد على العمل بكفاءة وفاعلية وعلى والئ

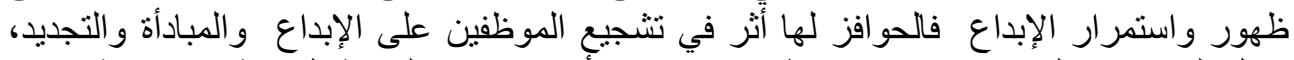

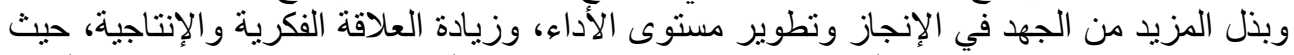

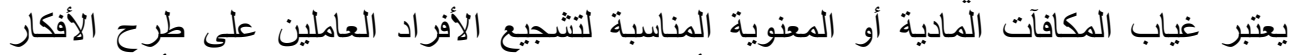

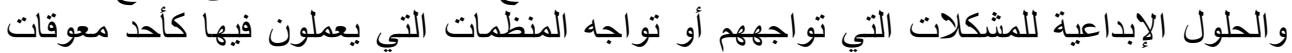

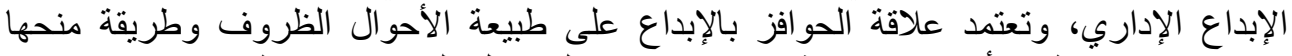

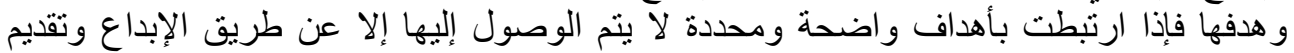

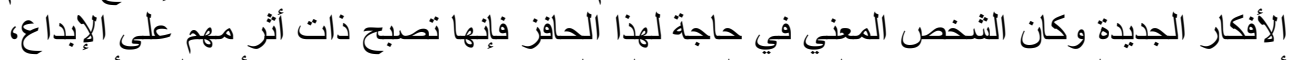

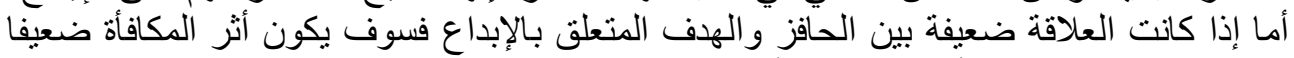

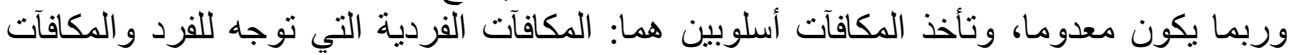

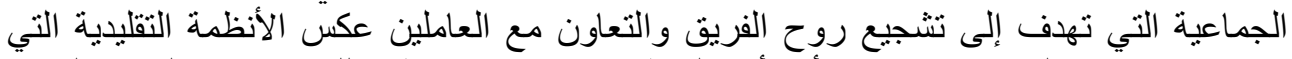

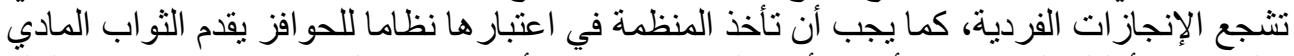

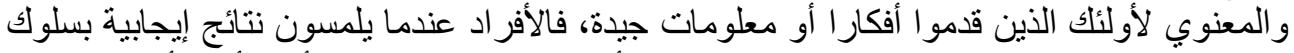

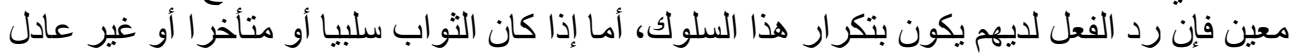

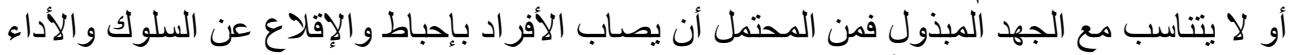

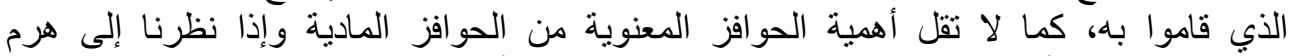

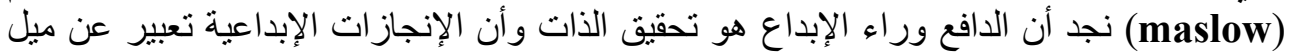

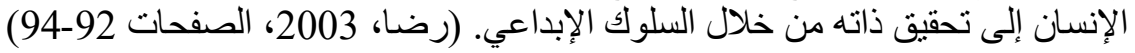




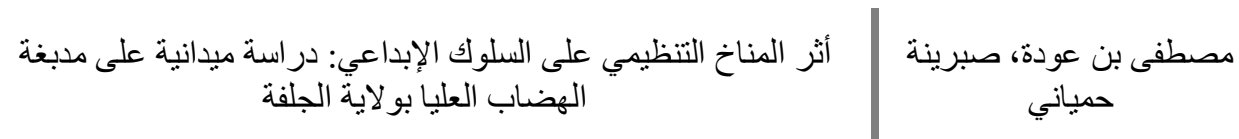

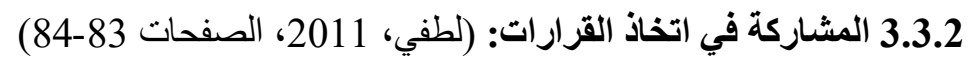

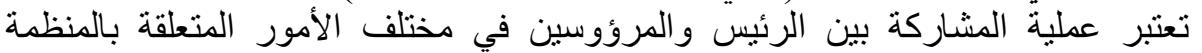

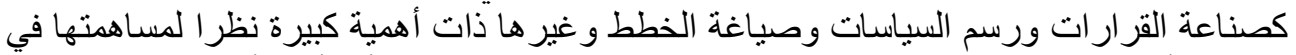

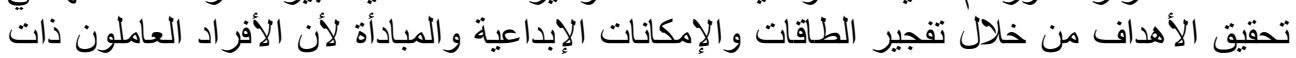

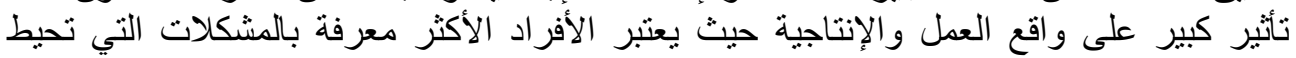

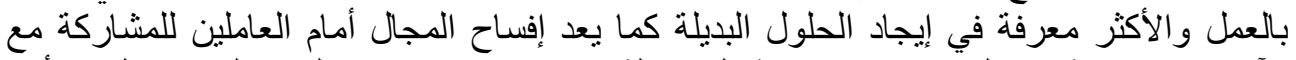

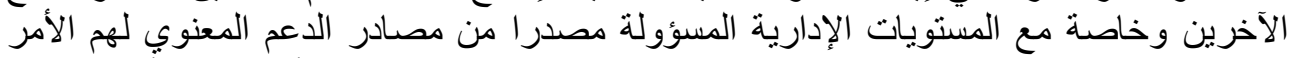

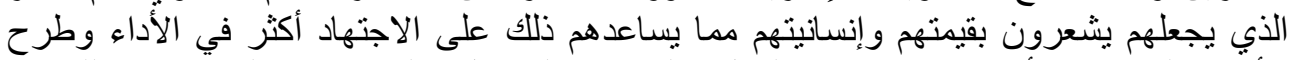

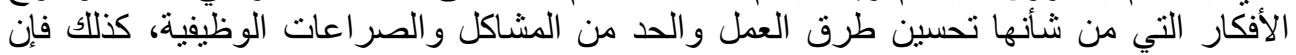

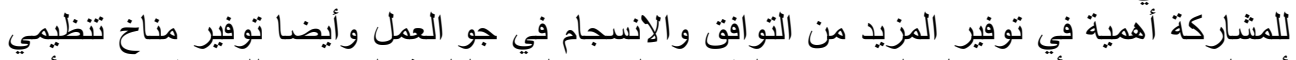

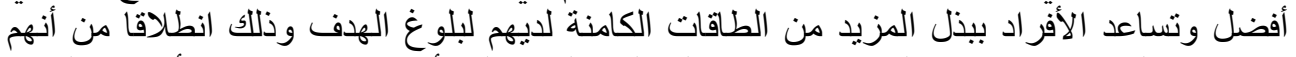

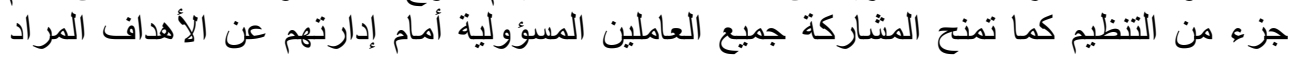

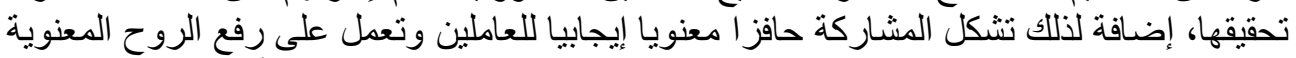

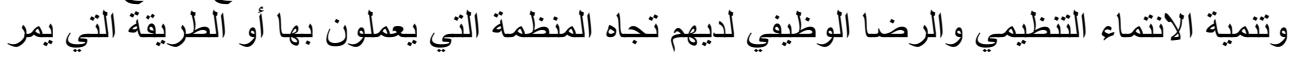

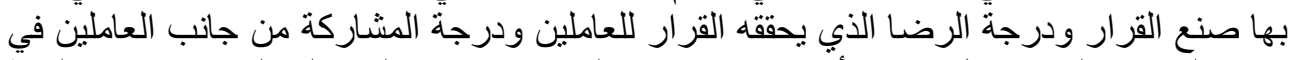

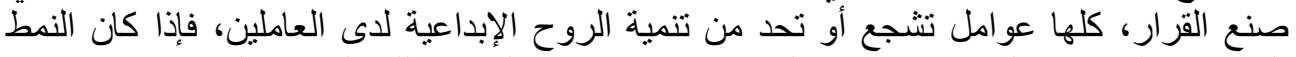

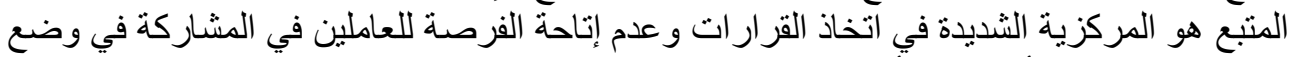

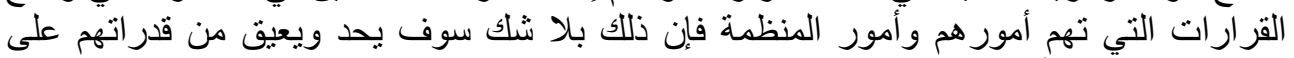

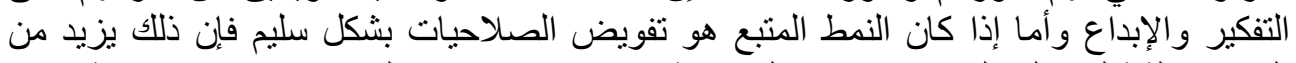

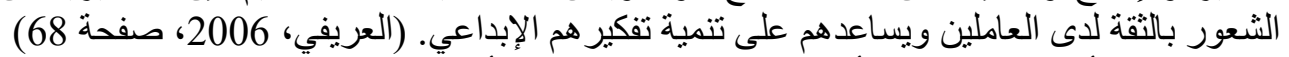

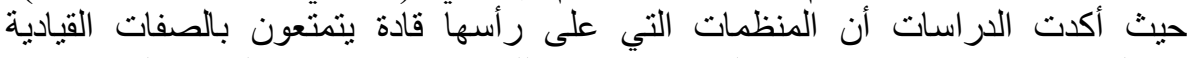

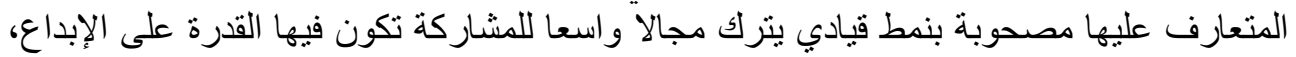

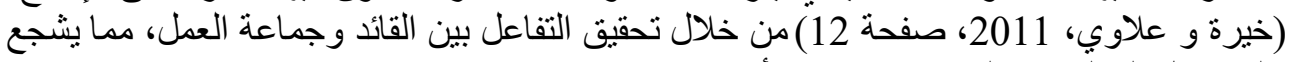

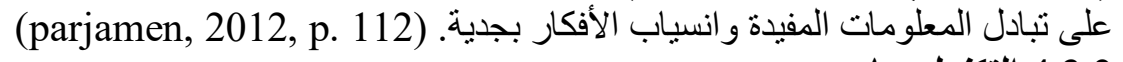

4.3.2 التكنولوجيا

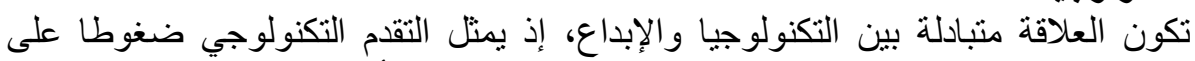

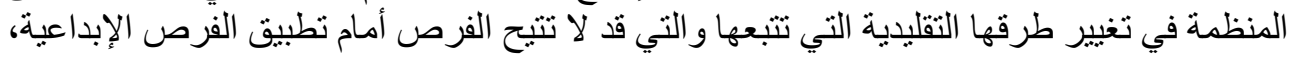

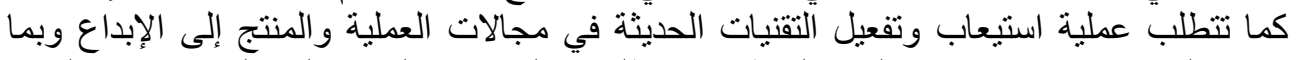

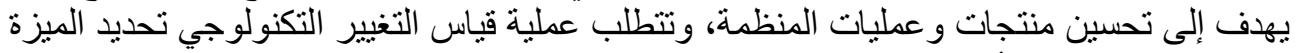

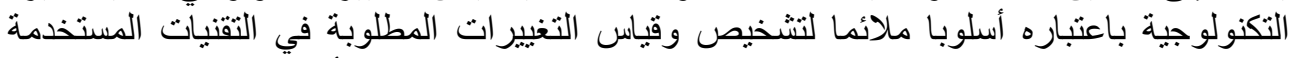

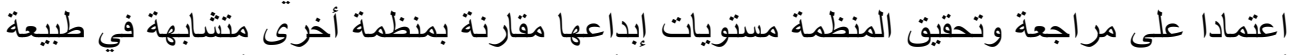

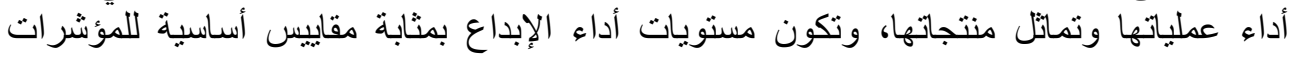

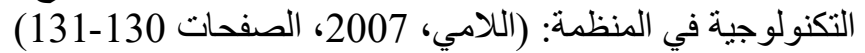

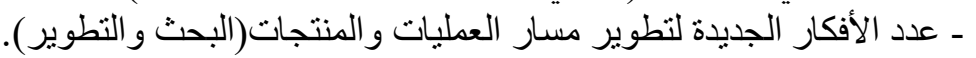
ـ عدد المنتجات الجديدة. - حالات تغيير وتطوير خطوط الجيدة، الانتاج الحالية. ـ ت نطوير الحصة السوقية.

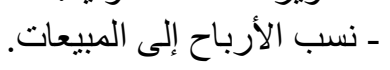


المجلد 01 العدد 04 (2019) ص 160-178 ص

يؤثر الانتماء التنظيمي على فعالية وكفاءة المنظمات لما له من نأثير على أداء العاملين

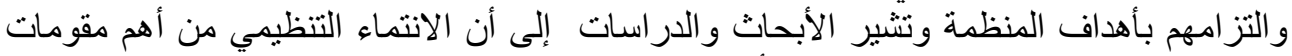

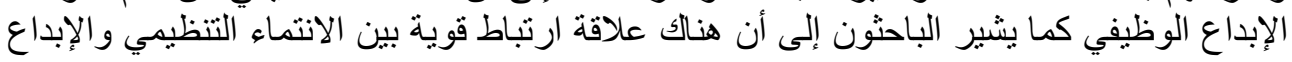
الإداري.

ويرجع كثير من باحثي الإدارة ومنظريها تفوق و إبداع الإدارة اليابانية إلى ارتفاع مستوى

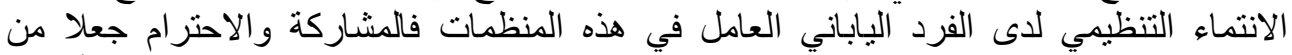

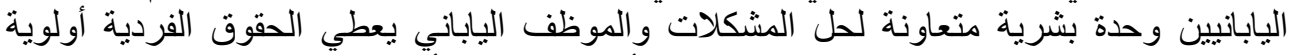

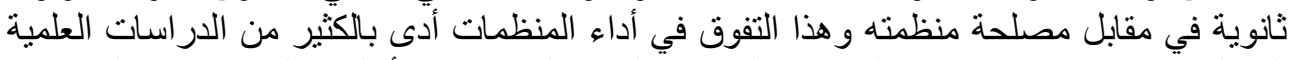

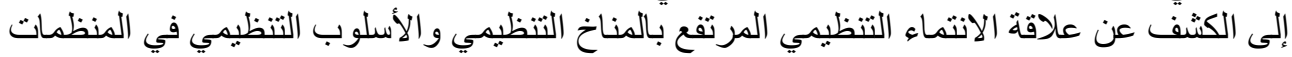

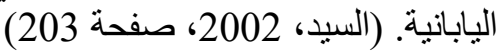

3. الإطار التطبيقي للار اسة

إن إسقاط الإطار النظري لموضوع الدراسة على أرض الواقع يتطلب كخطوة أولى توفير

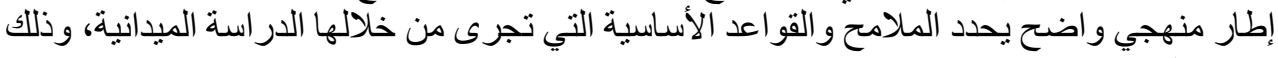

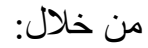

1.3 مجتمع وعينة الدراسة

بالنسبة لهذه الدراسة فمجتمع الدراسة فهو جميع العاملين بمدبغة الهضاب العليا بولاية الجلفة

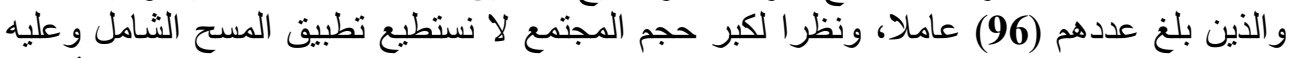

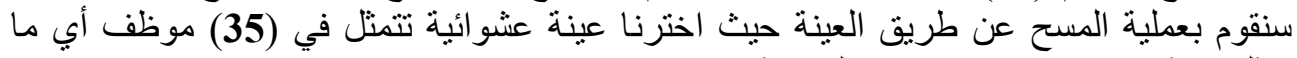

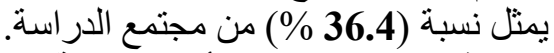
2.3 1.2 .3

ويقصد بـه التأكد من أن أداة الدر اسة (الاستبانة) صالحة لقياس ما أعدت من أجله، (العساف،

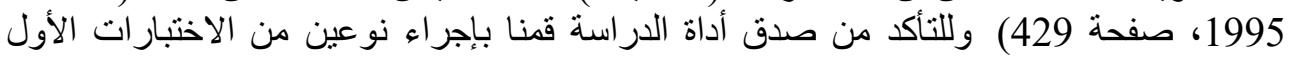
لقياس الصدق الظاهري، و الثاني لقياس الصدف الصند الداخلي.

قمنا بعرض الاستبيان على مجموعة من المحكمين تألفت من بعض أعضاء الهيئة التذريسية ـالصدق الظاهري

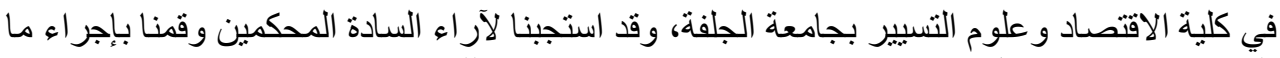
يلزم من حذف وتعديل في ضوء مقترحاتهم وتوصياتهم، وبذللك خرج الاستبيان في صورته شبه النهائية ليتم تطبيقه على عينة الدئ فئن استة الأساسية.

بعد التأكد من الصدق الظّاهي

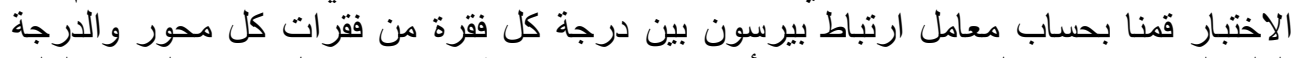

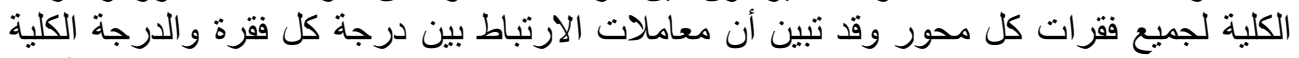

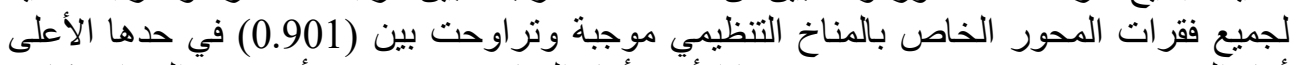

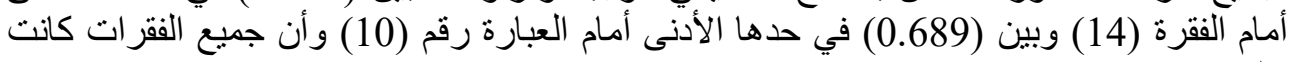
دالة إحصائيا عند مستوى معنوية يساوي (14) وبي (0.01). 
مصطفى بن عودة، صبرينة أثز المناخ التظيمي على السلوك الإبداعي: دراسة ميدانية على مدبغة

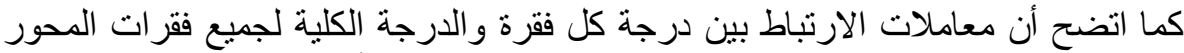

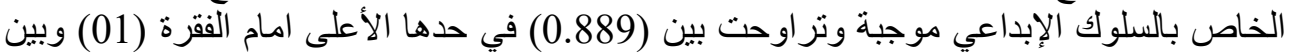

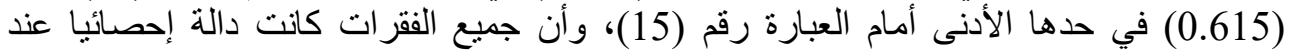

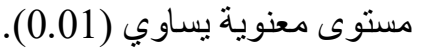

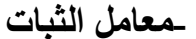

معامل الثبات لأداة الدراسة ككل (0.961) وهي قيمة ممتازة أما بالنسبة لمحور المناخ

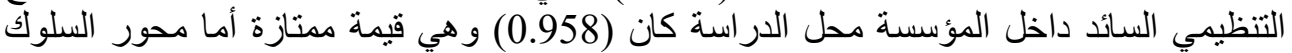
الإبداعي لدى العاملين بالمؤسسة محل الدراسة كان (0.919) وهي قيمة مهتازة أيضا.

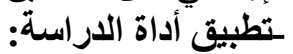
بعد أن تأكدنا من الصدة الأنداء الظاهري لأداة الدراسة بواسطة التحكيم، إذ قمنا على أساسه بإجر اء التعديلات اللازمة لإخر الناج النموذج النهائي للاستبانة.

\section{3}

سنعتمد في دراستتا على نتائج المعالجة الإحصائية التي توصلنا إلى تحديدها بعد تفريغ الإيخ

وتحليل بيانات الاستبانة باستخدام برنامج التحليل الاحصائي (SPSS).

1.3.3 تحليل البيانات الثخصية والئن الوظيفية جاءت النتائج موضحة في الجدول التالي:

جدول رقم 1: تحليل البيانات الثخصبة و الوظيفية حسب البيانات لعينة البحث

\begin{tabular}{|c|c|c|c|c|c|c|c|}
\hline المئوية & العدد & البيانات الثخصية & المتغير & المئوية & 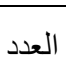 & البيانات الثخصية & المتغير \\
\hline$\% 45.5$ & 15 & تقني سامي & \multirow{4}{*}{ التعليمي } & $\% 84.8$ & 28 & ذكر & \multirow{2}{*}{ الجنس } \\
\hline$\% 27.3$ & 9 & ليسانس & & $\% 15.2$ & 05 & أنثى & \\
\hline$\% 6.1$ & 2 & ماجستير & & $\% 60.6$ & 20 & أقل من 35 سنة & \multirow{4}{*}{ العمر } \\
\hline$\% 21.2$ & 7 & مهندس & & $\% 33.3$ & 11 & بين 36 و49 سنة & \\
\hline$\% 51.5$ & 17 & 5 سنوات فأقل & \multirow{4}{*}{ سنوات الخبرة } & $\% 6.1$ & 2 & أكثر من 50 سنة & \\
\hline$\% 30.3$ & 10 & بين 6 و10 سنة & & $\% 60.6$ & 20 & أقل من 35 سنة & \\
\hline$\% 9.1$ & 3 & بين 11 و15 سنة & & $\% 24.2$ & 8 & دائمة & \multirow{2}{*}{ الوظبيفة } \\
\hline$\% 9.1$ & 3 & أكثر من 15 سنة & & 0758 & 25 & مؤقتة & \\
\hline
\end{tabular}

المصدر : من إعداد الباحثين بناء على مخرجات برنامج (Spss).

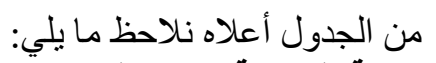

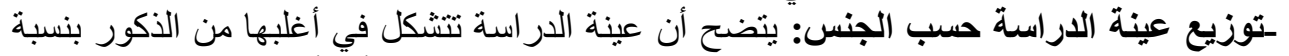

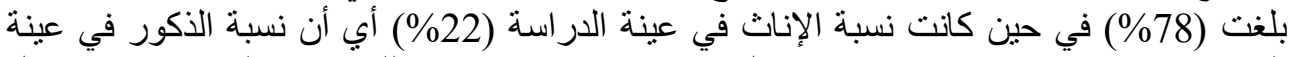

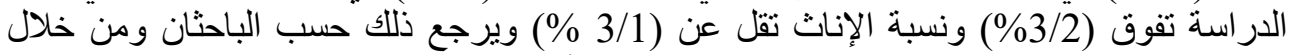

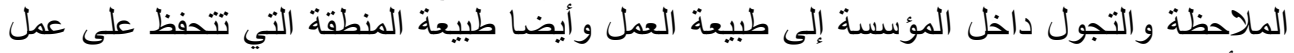

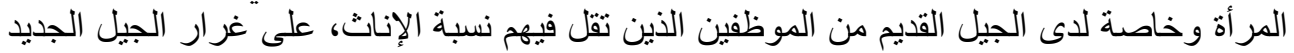

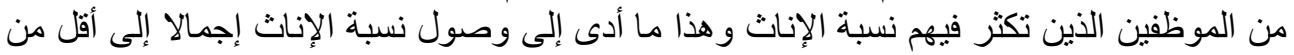
الثلث في عينة الدراسة. 
المجلد 01 العدد 04 (2019) ص 160-178 ص

تتوزيع عينة الداسة حسب العمر: يتضح أن الفئة العمرية الغلالبة على أفراد في عينة الدر اسة هي

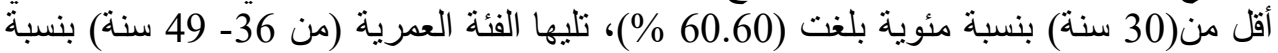

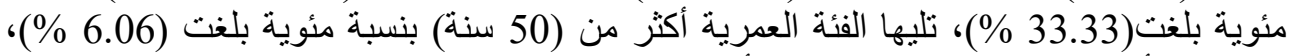

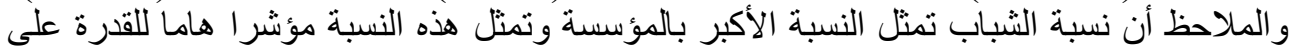
التطور و الإبداع. -توزيع عينة الأراسة حسب المستوى التعليمي: يتضح أن المؤهل العلمي الغالب على أفراد عينة

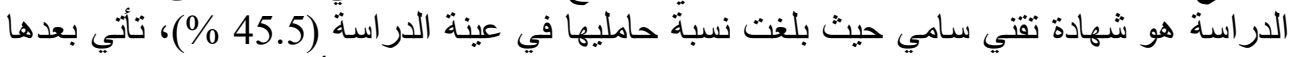

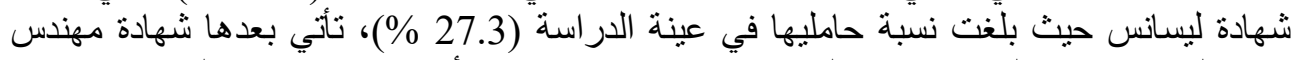

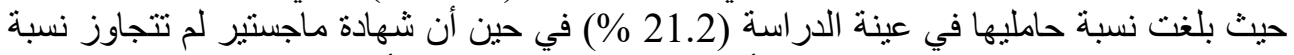

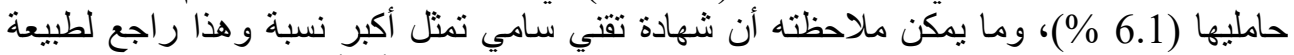

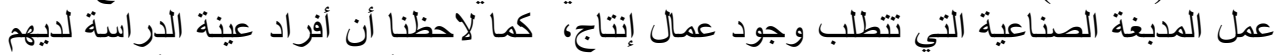

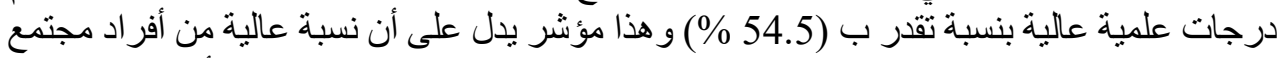

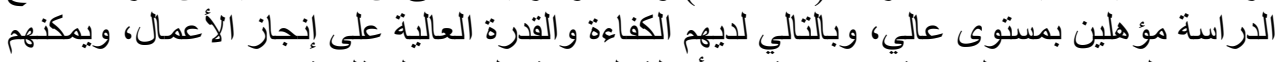

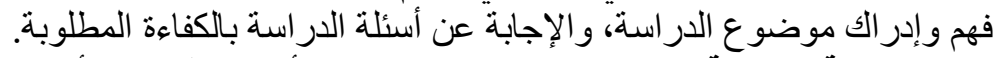

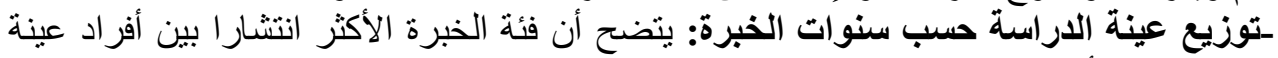

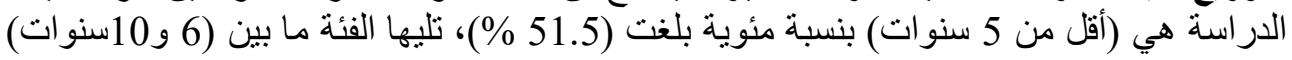

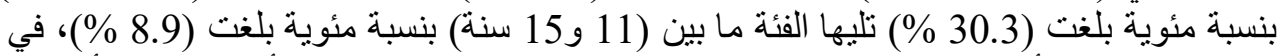

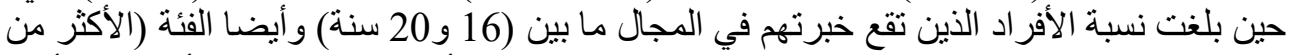

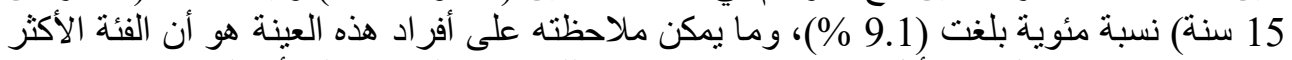

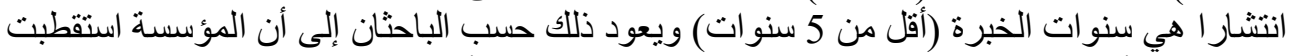

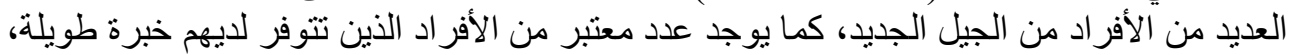

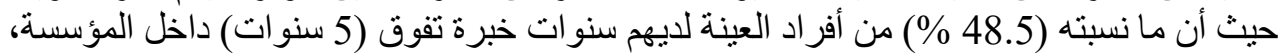

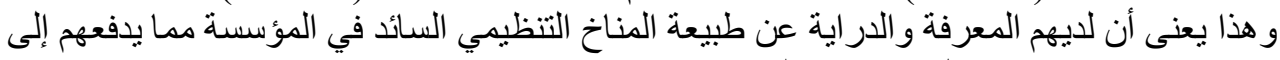

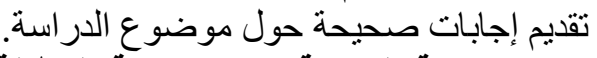
-توزيع عينة الاراسة حسب تسمية الوظيفة: يتضح أن الولة الوظيفة الأكثر انتشارا بين أفراد عينة

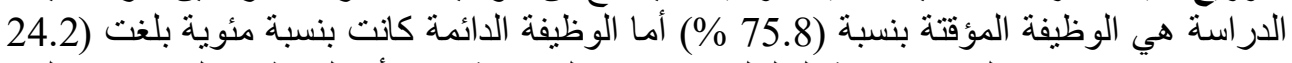

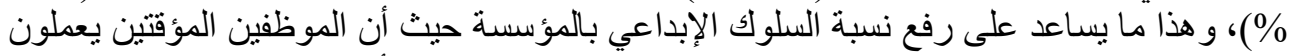

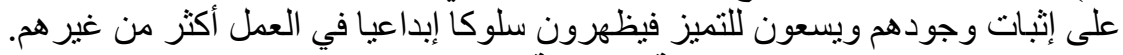

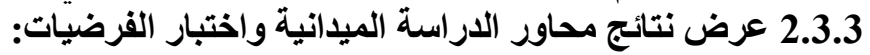

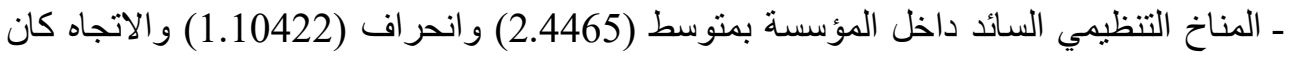
نادرا. ـ السلوك الإبداعي داخل المؤسسة بمتوسط (2.7697) و انحراف (1.31001) بينما الاتجاه كان أحيانا. سنقوم باختبار صحة فرضية الدر اسة الميدانية والتي جاءت على النحو الآتي: 1.2.3.3 نتائج اختبار الفرضية الأولى فئل

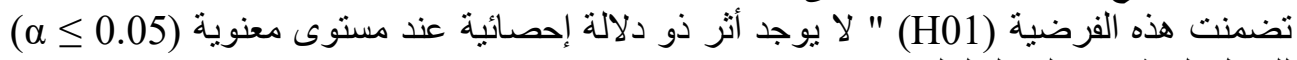

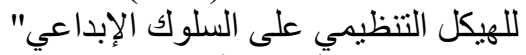

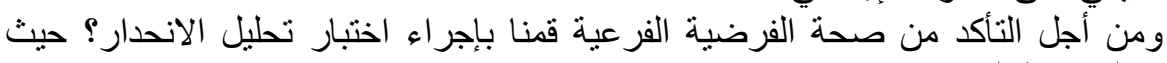
توصلنا إلى النتائج التالية: 
مصطفى بن عودة، صبرينة أثر المناخ التظظيمي على السلوك الإبداعي: دراسة ميدانية على مدبغة جدول رقم 2: تحليل الانحدار البسيط لأثر الهيكل التنظيمي على السلوك الإبداعي

\begin{tabular}{|c|c|c|c|c|}
\hline وجود أثز أو عدم وجوده & مستوى دلالة t & t المحسوبة t & $\beta$ & المتغير ات \\
\hline 1 & 0.006 & 2.984 & 1.008 & الثابت \\
\hline يوجد أثر & 0.000 & 5.913 & 0.782 & الهيكل التنظيمي \\
\hline & & & 0.530 & $\mathrm{R}^{2}$ \\
\hline & & & 0.000 & Fلالة F \\
\hline & & & $\mathrm{Y}=1.008+782 \mathrm{x}$ & المعادلة \\
\hline
\end{tabular}

المصدر : من إعداد الباحثين بناء على مخرجات برنامج (Spss).

من خلال الجدول أعلاه نجد أن قيمة معامل التحديد (R2 =0.530) و هذا يعني أن التغير في

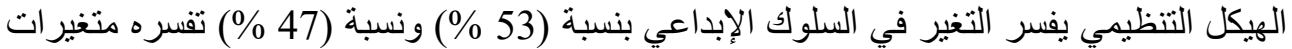
كما نلاحظ من الجدول أن دلالة اختبار فيشر تساوي (0.000) وبالتالي هي أقل من (0.05)

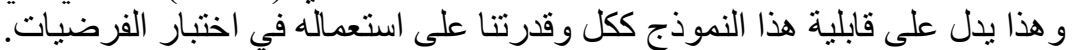

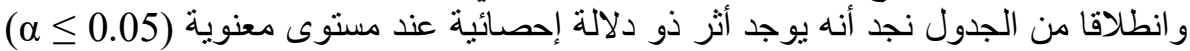

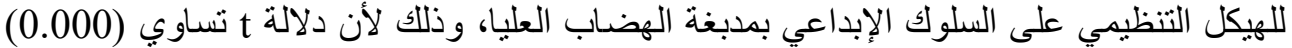
و هي أقل من (0.05)، ومنه نقبل H1 ونرفض H0 Hيعود ذلإلك إلى إحساس العاملين بأن قنوات

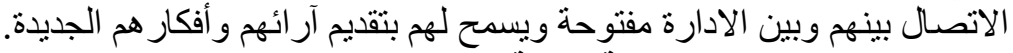

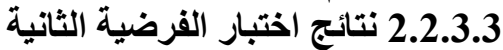
تضمنت هذه الفرضية (H02) " لا يوجد أثز ذو دلالة إحصائية عند مستوى معنوية (1)

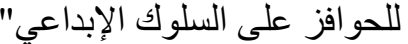
ومن أجل التأكد من صحة الإبدي الفرضية قمنا باختبار تحليل الانحدار البسيط حيث توصلنا إلى

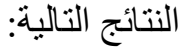
جدول رقم 3: تحليل الانحدار البسيط لأثر الحو افز على السلوك الإبداعي

\begin{tabular}{|c|c|c|c|c|}
\hline وجود أثز أو عدم وجوده & t & t المحسوبة t & $\beta$ & المتغير ات \\
\hline 1 & 0.004 & 3.120 & 1.179 & الثابت \\
\hline يوجد أثر & 0.000 & 4.760 & 0.656 & الحو افز \\
\hline & & & 0.422 & $\mathrm{R}^{2}$ \\
\hline & & & 0.000 & ملالة F \\
\hline & & & $Y=1.179+0.656 X$ & المعادلة \\
\hline
\end{tabular}

المصدر : من إعداد الباحثين بناء على مخرجات برنامج (Spss).

من خلال الجدول أعلاه نجد أن قيمة معامل التحديد (R²=0.422) و هذا يعني أن التغير في الحوافز يفسر التغير في السلوك الإبداعي بنسبة (42.2 \% \% منسبة (57.8 \% \%) تفسره متغيرات كما نلاحظ من الجدول أن دلالة اختبار فيشر تساوي (0.000) وبالتالي هي أقل من (0.05)

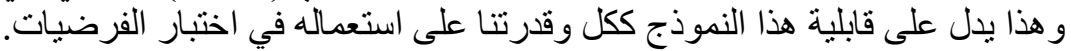

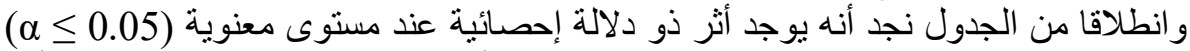

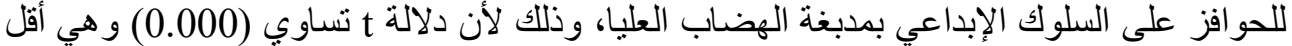

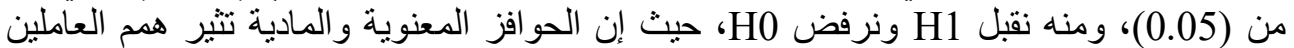

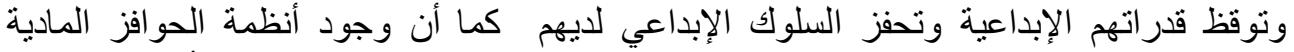
و المعنوية الايجابية والسلبية وتطبيقها بشكل عادل ومستند على معايير واضحة للأداء يؤدي إدي إلى 
|المجلد 01 العدد 04 (2019) ص 160-178 ص

خلق مناخ تنظيمي يدفع العاملين إلى العمل بكفاءة وتنفيذ قرارات الادارة ويشجعهم على المنافسة 3.2.3.3 نتائج اختبار الفرضية الثالثة

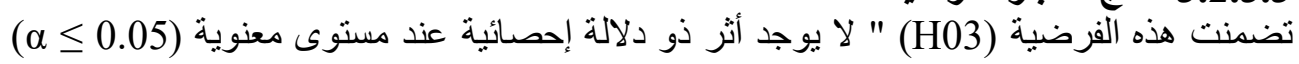

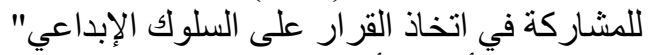
ومن أجل التنأكد من صحة الفر الفيلة الفيداعي" الفرعية قمنا بإجر اء اختبار تحليل الانحدار البسيط حيث توصلنا إلى النتائج التالية:

\begin{tabular}{|c|c|c|c|c|}
\hline وجود أثثر أَّ عدم وجوده & مستوى دلالة t & t المحسوبة t & B & المتغير ات \\
\hline 7 & 0.065 & 1.915 & 0.763 & الثابت \\
\hline يو بو أثر & 0.000 & 5.525 & 0.801 & المشاركة في اتخاذ القرار \\
\hline & & & 0.496 & $\mathrm{R}^{2}$ \\
\hline & & & 0.000 & Fلالة F F F \\
\hline & & & $\mathrm{Y}=0.763+0.801 \mathrm{X}$ & 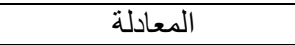 \\
\hline
\end{tabular}

المصدر : من إعداد الباحثين بناء على مخرجات برنامج (Spss).

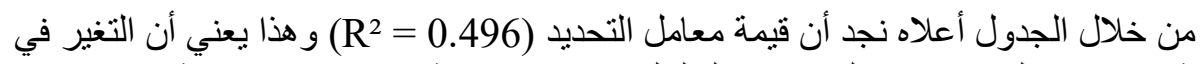

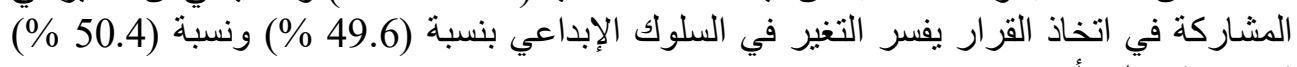

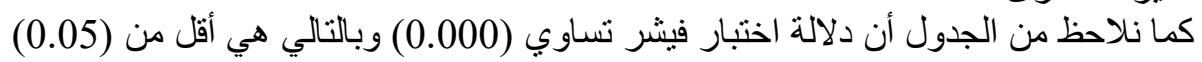

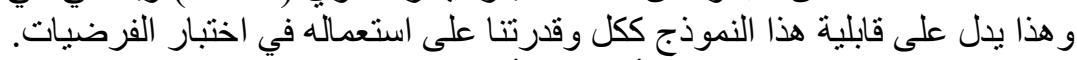

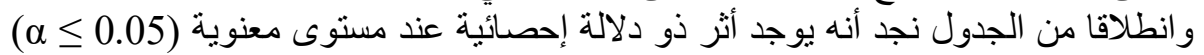

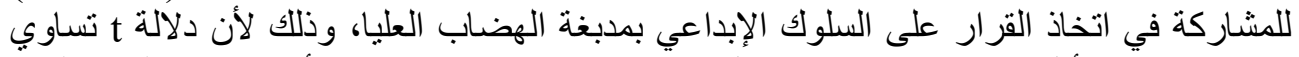

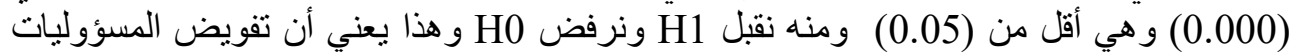

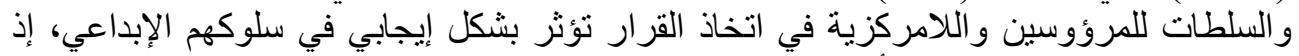

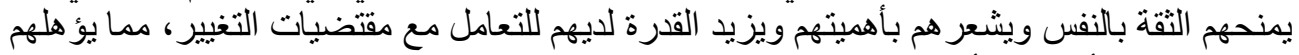

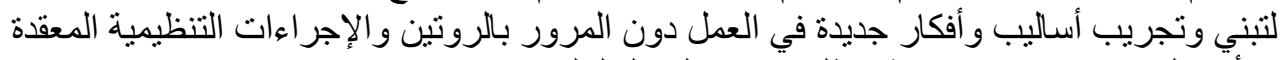

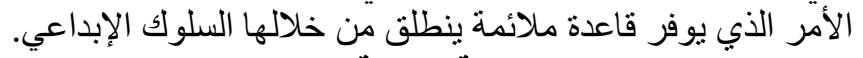

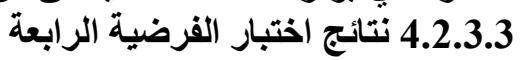

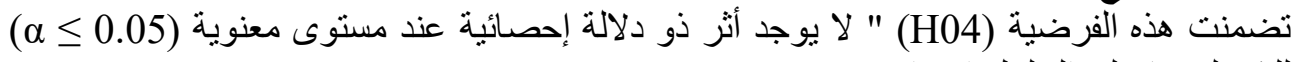

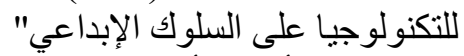
ومن أجل التأكد من صحة الفرضية الإبل الفرعية قمنا بإجر اء اختبار تحليل الانحدار البسيط حيث توصلنا إلى النتائج النالية: جدول رقم 5: تحليل الانحدار البسيط لأثر التكنولوجيا على السلوك الإبداعي

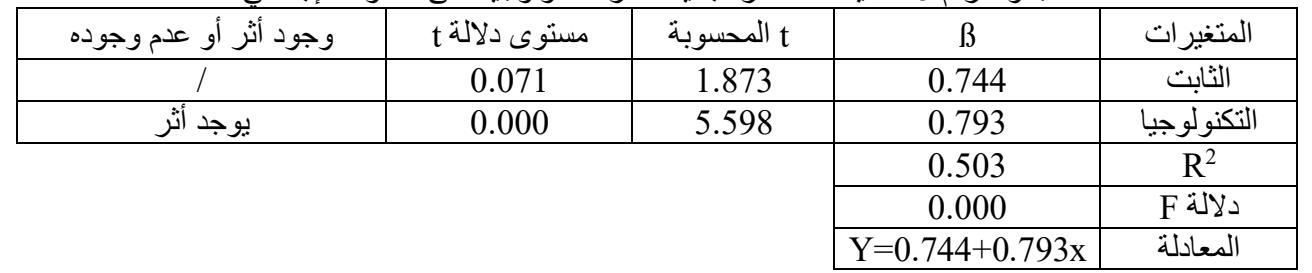

الدصدر: من إعداد الباحثين بناء على مخرجات برنامج (Spss). 
مصطفى بن عودة، صبرينة أثر المناخ التظظيمي على السلوك الإبداعي: دراسة ميدانية على مدبغة

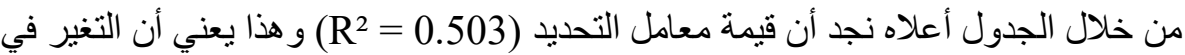

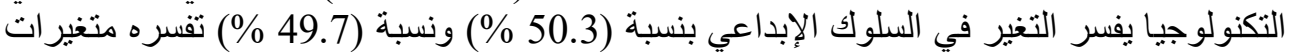

كما نلاحظ من الجدول أن دلالة اختبار فيشر تساوي (0.000) وبالتالي هي أقل من (0.05)

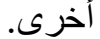

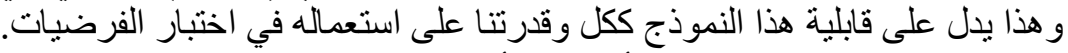

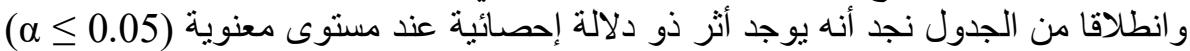

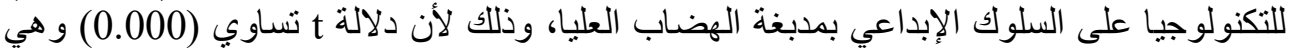

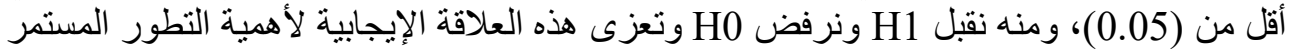

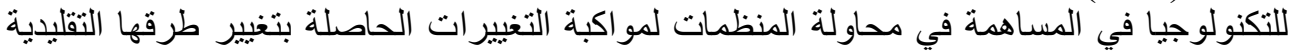

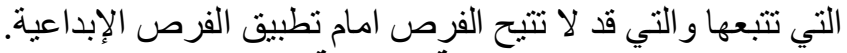

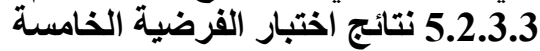

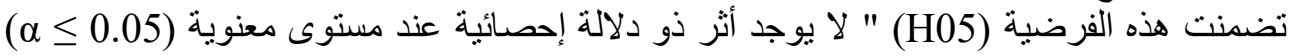

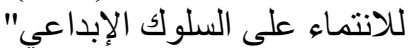
ومن أجل التأكد من صحة الإبلهة الفرضية الفرعية قمنا بإجراء اختبار تحليل الانحدار البسيط حيث توصلنا إلى النتائج التنالية:

جدول رقم 6: تحليل الانحدار البسيط لأثر الانتماء التنظيمي على السلوك الإبداعي التي

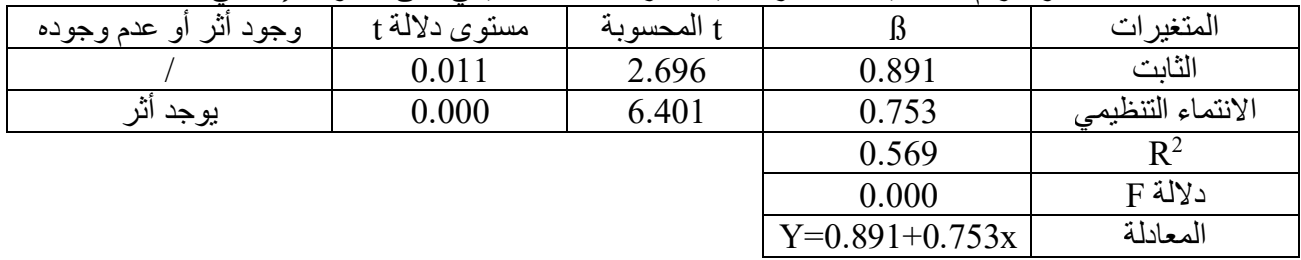

المصدر : من إعداد الباحثين بناء على مخرجات برنامج (Spss).

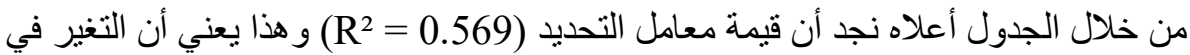
الانتماء التنظيمي يفسر التغير في السلوك الإبداعي بنسبة (56.9 \% \%) ونسبة (43.1 و \% كما نلاحظ من الجدول أن دلالة اختبار فيشر تساوي (0.000) وبالتالي هي أقل من (0.05)

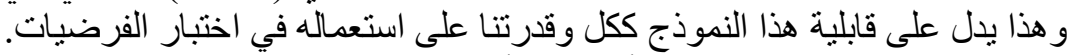

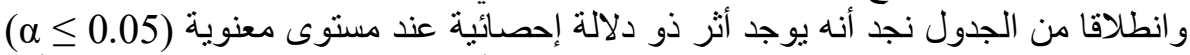

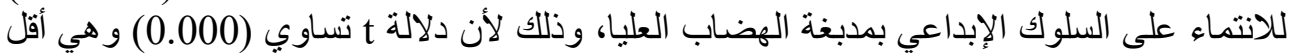

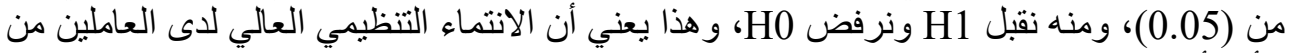

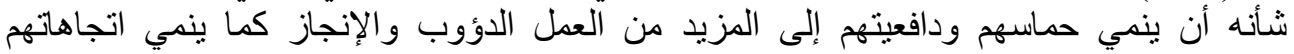
الإيجابية نحو المبادرة و الإبداع.

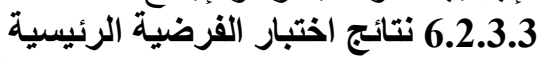

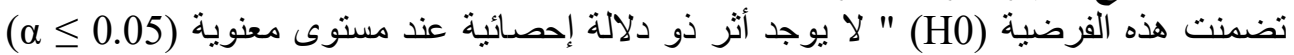

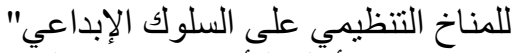
ومن أجل التأكد من صحة الفرضية الفئية الفربة قمنا بإجر اء اختبار تحليل الانحدار البسيط حيث

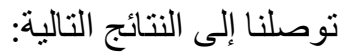


|المجلد 01 العدد 04 (2019) ص 160-178 ص

مجلـة بحوث الإدارة و الاقتصاد

الجدول رقم 7: تحليل الانحدار البسيط لأثر المناخ التنظيمي على السلوك الإبداعي

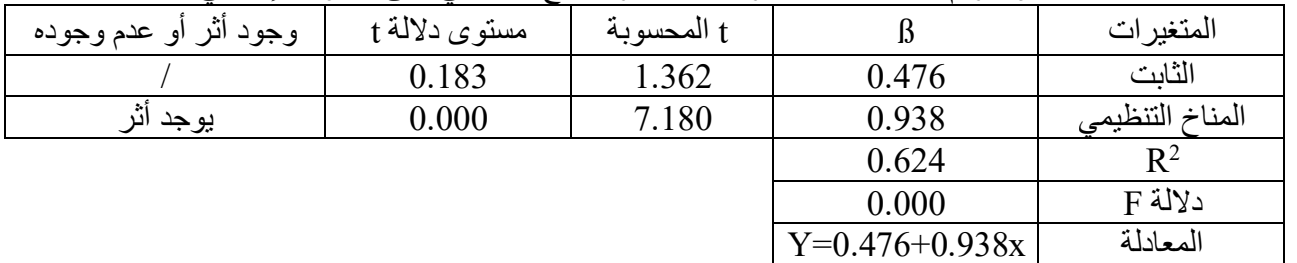

المصدر : من إعداد الباحثين بناء على مخرجات برنامج (Spss).

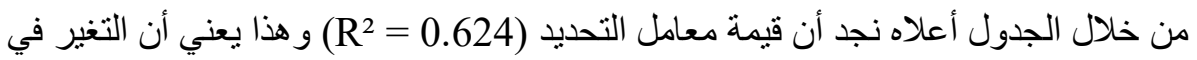

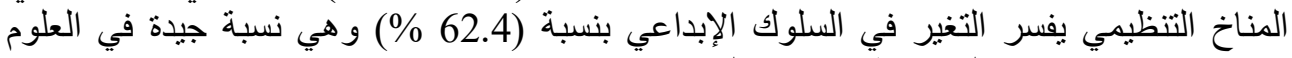

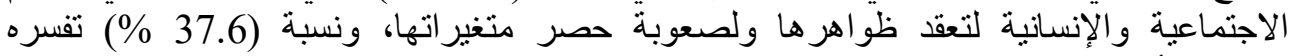
كما نلاحظ من الجدول أن دلالة اختبار فيشر تساوي (0.000) وبالتالي هي أقل من (0.05)

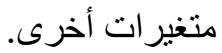

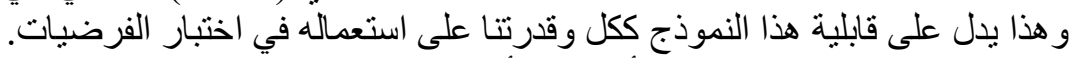

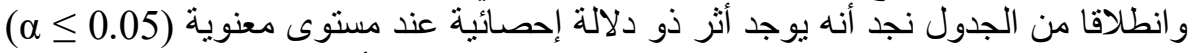

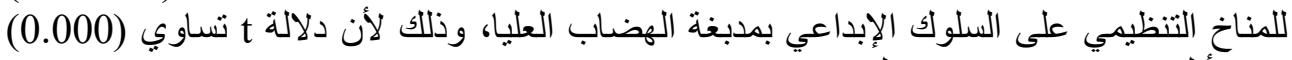

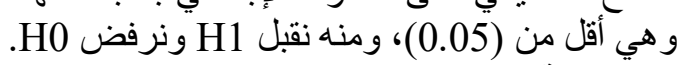

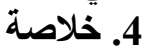
ـنتائج الدراسة النظرية: مـن خـلال بحثنـا في الجانب النظري توصلنا إلى مجموعـة مـن النتـائج

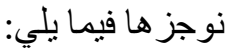
ليعد المناخ التنظيمي من أهم مكونات البيئة الداخلية التي تختلف من بيئـة إلى أخرى و التي تؤثر

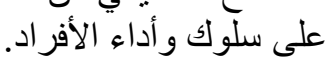

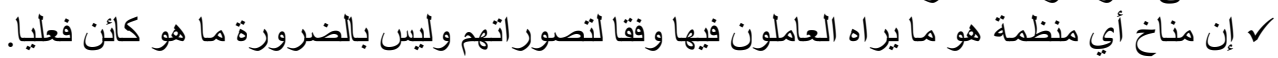

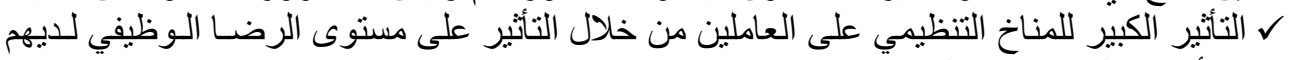
و أيضا على دافعينهم للإنجاز الإنير.

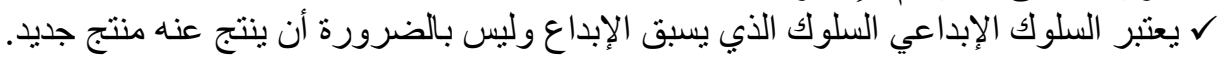

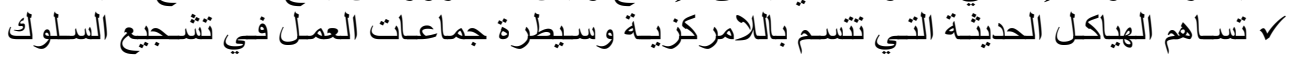
الإبداعي.

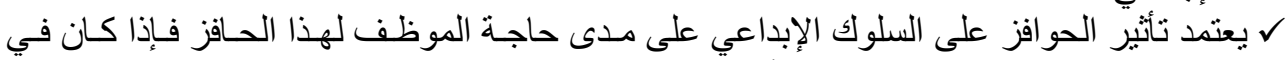

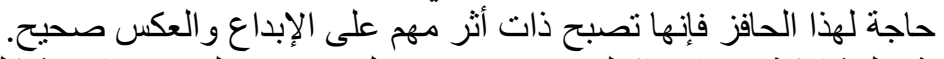

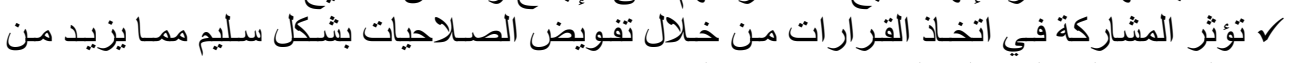

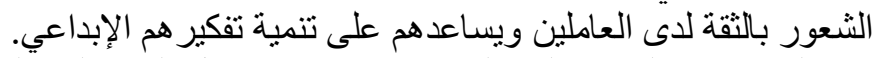

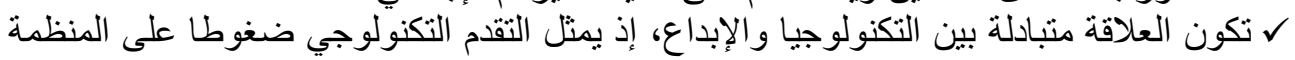
في تغيير طرقها التقليدية كما تتطلب عملية تفعيل التيلة التقنيات الحديثة إلى الإبداع. نتائج اختبار الفرضيات:

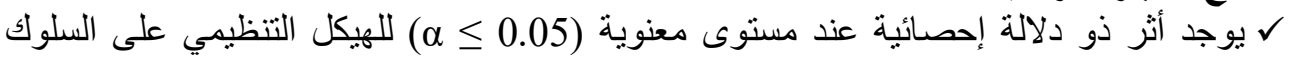

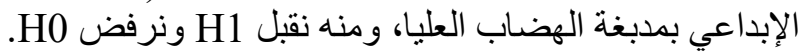

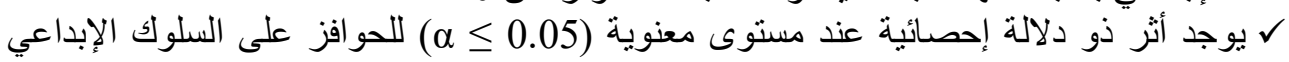

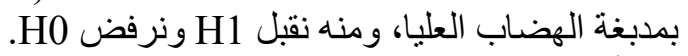
ليوجد أثر ذو دلالة إحصائية عند مستوى معنوية (2 السلوك الإبداعي بمدبغة الهضاب العلية العنا، ومنه نقبل H1 ونرفض 
مصطفى بن عودة، صبرينة أثر المناخ التنظيمي على السلوك الإبداعي: دراسة ميدانية الجلفة على مدبغة

ل يوجد أثر ذو دلالة إحصائية عند مستوى معنوية (1 0.05$)$ للتكنولوجيا على السلوك الإبداعي بمدبغة الهضاب العليا، ومنه نقبل

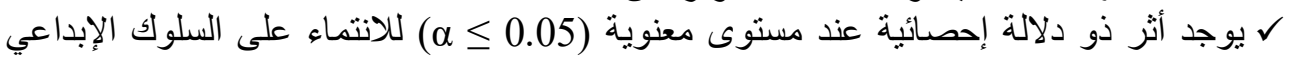
بمدبغة الهضاب العليا، ومنه نقبل

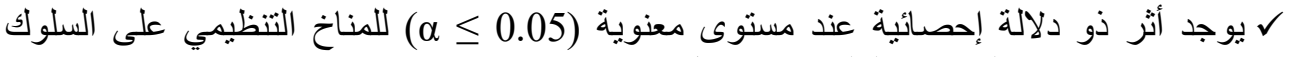
الإبداعي بمدبغة الهضاب العليا، ومنه نقبل ـ الاقتر احاث والتوصي لاعديات:

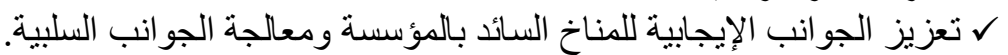

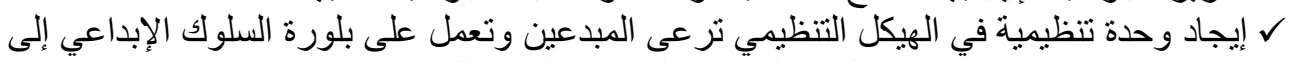

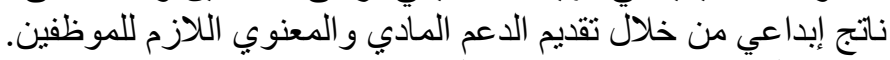

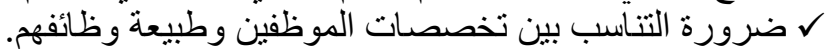

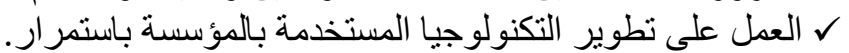

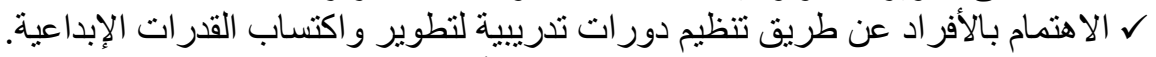

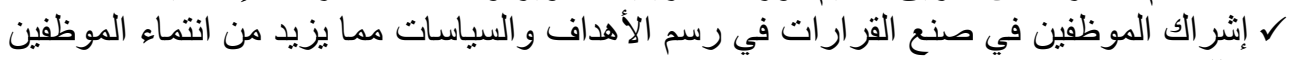
للمنظمة المنر المون. لإجراء المزيد من الدراسات حول المناخ التتظيمي لتشمل أبعاداً أوسع من الأبعاد التي تنتاولتها

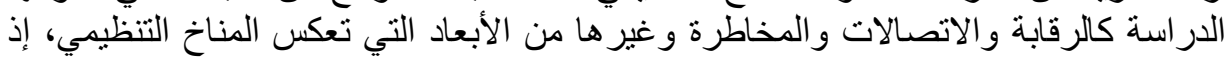

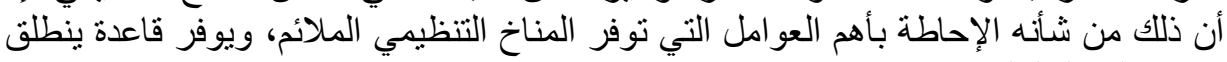

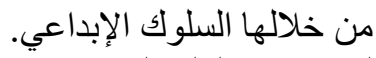

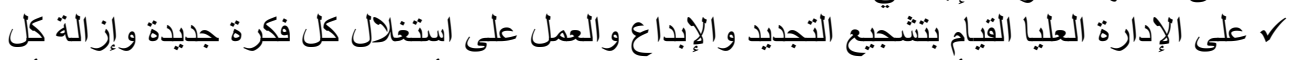

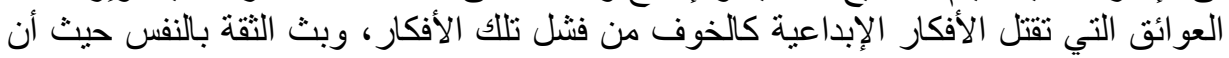

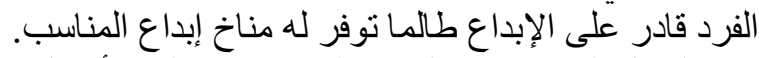

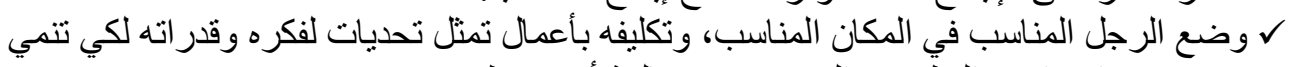

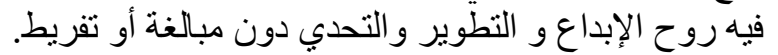

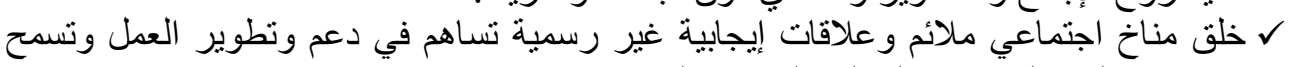

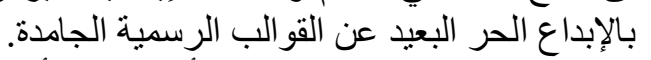

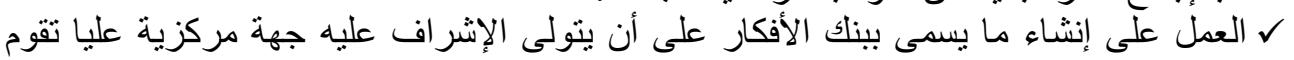

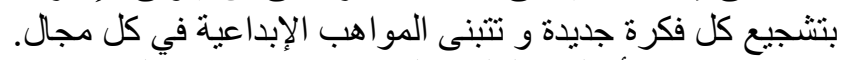

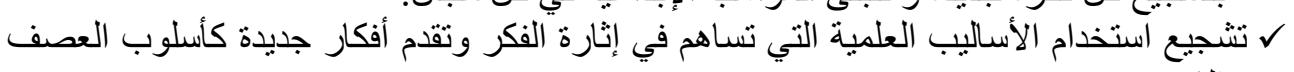

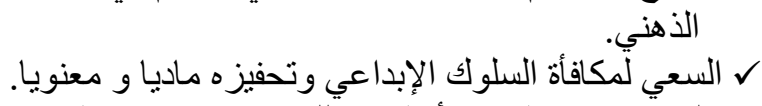

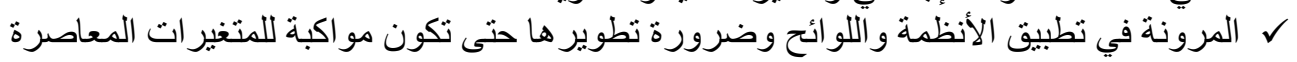

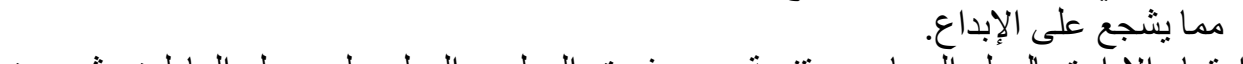
لاهتمام الإدارة بالعمل الإبدأُ الجماعي وتتمية روح فريق العمل، والعمل على جعل العاملين يشعرون

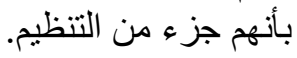


سعود بن محمد العريفي، (2006)، المعوقات التنظيمية لإبداع العاملين، رسالة ماجستير في الإدارة العامة، كلية الاقتصاد و الإدارة جامعة الملاك عبد العزيز، السعودية.

لؤي فواز محمد بطانية، أثر التمكين و الدعم التنظيمي في السلوك الإبداعي للعاملين في القطاع العام الأردني، رسالة ماجستير في

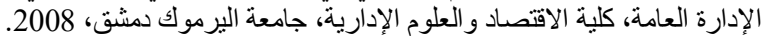

أبو بكر مصطفى بعيرة، (1988)، دور المناخ الإداري في تلتمية القوى العاملة في داخل المنظمة، مجلة المبلة الملك عبد العزيز الاقتصاد

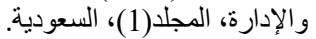

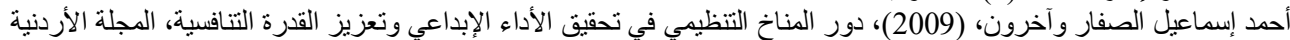
في إدارة الأعمال، المجلد 5 (العدد 3).

أثنرف أحمد سليم، (2009)، السلوك القبادي و علاقتته بالمناخ المنظمي لدى مديري المدارس الحكومية الثانوية في محافظات شمال الضفة الغربية من وجهة نظر معلميهم، رسالة ماجستير في الإدارة التربوية، كلية الدراسات العلئا، جامعة النجاح النياح الوطنية، نابلس.

حاتم علي حسن رضا، (2003)، الإبداع الإداري و علاقته بالأداء الوظيفي، رسالة ماجستير في العلوم الإدارية كلية الدراسات العليا، أكاديمية نايف العربية للعلوم الأمنية، الرياض.

حامد كاظم متعب، عامر علي العطوي، (2007)، دور المنافية الإناخ التنظيمي في تعزيز سلوك نشر المعرفة في المؤسسات التعليمية مجلة

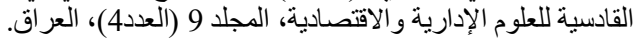

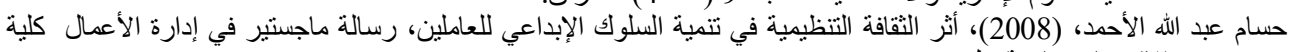

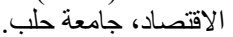

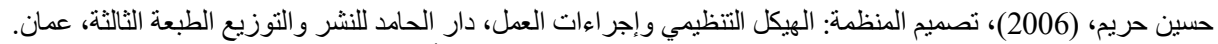

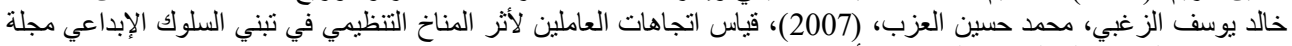
المنارة، المجلد 13 (العدد2)، الأردن.

سعيد بن عبد الله ناصر الثقصي، (2011)، فاعلية التشريعات التعليمية في نوجيه المناخ التنظئيمي في المؤسسات التعليمية في سلطنة

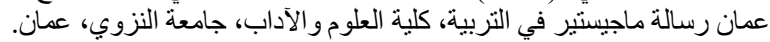

سيد عيد خبير، (17-21 فبراير 2008)، التحديات التي نواجه الإدارة الإبداعية، ندوة علئية الإدارة الإبداعية للبرامج والأنشطة في

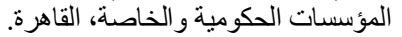

عاكف لطفي، (2011)، إدارة الإبداع و الابتكار في منظمات الأعمال، دار الحامد للنشر و التوزيع، الطبعة الأولى، عمان. عبد الله عوض الحارثي، (2013)، المناخ التنظيمي و علاقته بالرضا، رسالة ماجيستير في الادارة التربوية والتخطيط، كلية الترائ التربية، جامعة أم القرى، السعودية.

عيشوش خيرة، علاوي نصيرة، (13، 14 ديسمبر 2011)، دور المنظمات المتعلمة في تشجيع عملية الابداع، ملتقى دولي حول:

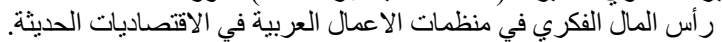

غسان قاسم اللامي، (2007)، إدارة التكنولوجيا: مفاهيم ومداخل تقنيات تطبيقات عملية، دار المناهج للإنشر و التوزيع الطبعة الأولى، عمان.

كريم ناصر علي، سوزان غلام رضا علي، (2014)، المناخ التنظيمي في الجامعة المستتصرية من وجهة نظر الهيئة التدريسية مجلة

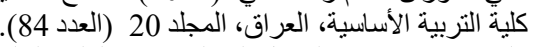

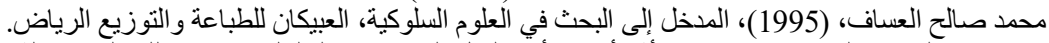

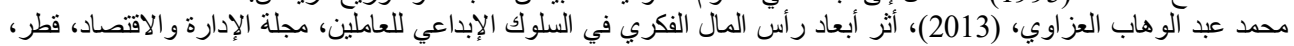

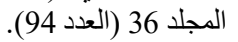

محمد عجيلة، (2005)، الإبداع في المؤسسة الاقتصادية الجز ائرية: دراسة لصفات ولإدة ومعوقات ومحفز ات الإبداع، رسالة ماجستير في

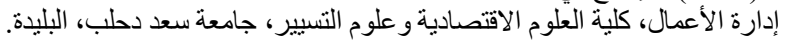

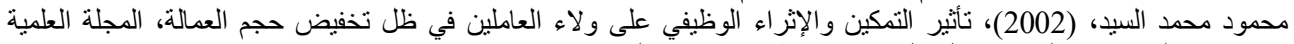

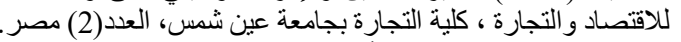

مؤيد سعيد السالم، (2699)، العاد (1999)، العلاقة بين أبعاد نصميم العمل و السلوك الإبداعي للعاملين، مجلة دراسات العلوم الإدارية، الأردن،

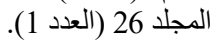

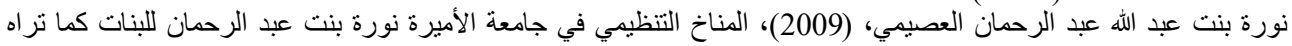

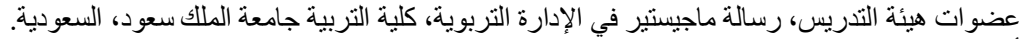

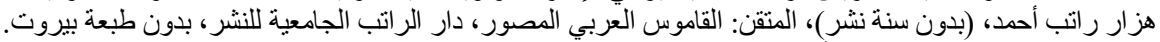

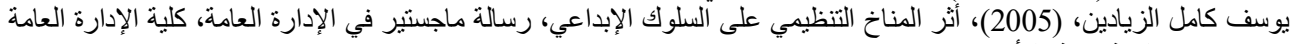

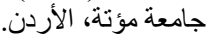

Parjanen, S. (2012). Experiencing creativity in the organization: From individual creativity to collective creativity. Interdisciplinary Journal of Information, Knowledge \& Management, 7. 


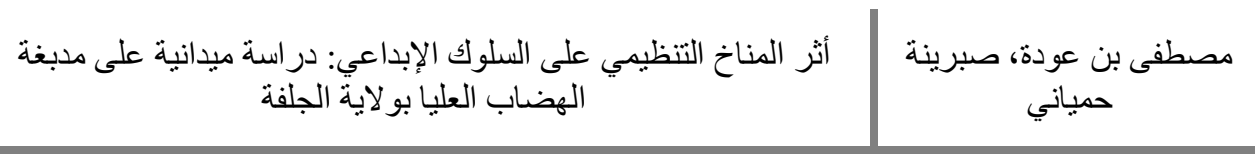

\section{References}

Al-Arifi. S. B. (2006). Organizational Obstacles to Employee Creativity, (Master Thesis, King Abdulaziz University, Saudi Arabia). [In Arabic]

Battaniya, L. F. M. (2008). The Impact of Empowerment and Organizational Support on the Creative Behavior of workers in the Jordanian Public Sector, (Master Thesis, Yarmouk University). [In Arabic]

Baira, A. M. (1988). the role of the administrative climate in the development of the workforce within the organization, King Abd-laziz Journal of Economics and Administration, 1. [In Arabic]

Al-Saffar, A. I., \& all. (2009). The role of the organizational climate in achieving creative performance and strengthening competitiveness, Jordanian Journal of Business Administration, 5 (3). [In Arabic]

Ashraf, A. S. (2009). Leadership behaviour and its relationship to the organizational climate among government secondary school principals in the northern West Bank governorates from the viewpoint of their teachers, (Master Thesis, An-Najah National University, Nablus). [In Arabic]

Reda, H. A. H. (2003). administrative creativity and its relationship to job performance, (Master Thesis, Naif Arab Academy for Security Sciences, KSA). [In Arabic]

Muteb, H. K., \& Al-Atwi, A. A. (2007). The Role of the Organizational Climate in Promoting Knowledge Dissemination in Educational Institutions Al-Qadisiyah Journal of Administrative and Economic Sciences, 9 (4). [In Arabic]

Al-Ahmad, H. A. (2008). The Impact of Organizational Culture on Developing Creative Behavior of Workers, (Master Thesis, University of Aleppo).[In Arabic]

Harim, H. (2006). Organization Design: Organizational Structure and Working Procedures, Dar AlHamid for Publishing and Distribution, $3^{\text {rd }}$ edition, Jordan. [In Arabic]

Al-Zoghbi, K. Y., \& Al-Azab, M. H. (2007), Measuring Workers Attitudes on the Impact of Organizational Climate on Adopting Creative Behavior, Al-Manara journal, Volume 13 (2). [In Arabic]

Al-Shaqsi, S. B. N. (2011), Effectiveness of Educational Instructions in Educational Institutions in the Sultanate of Oman, (Master Thesis, University of Nizwa, Oman). [In Arabic]

Khabir, S. E. (February 17-21, 2008), Challenges Facing Creative Management, A seminar on Creative Management of Programs and Activities in Governmental and Private Institutions, Cairo. [In Arabic]

Akef, L. (2011), Managing Creativity and Innovation in Business Organizations, Dar Al-Hamid for Publishing and Distribution, $1^{\text {st }}$ Edition, Jordan. [In Arabic]

Al-Harthi, A. A. (2013), Organizational climate and its relationship to satisfaction, (Master Thesis, Oum Al-Qura University, Saudi Arabia). [In Arabic]

Aychuch, K., \& Allawi, N. (13, 14 December 2011). The role of Learned organizations in encouraging the creative process, an international forum on intellectual capital in Arab business organizations in modern economies. [In Arabic]

Al-Lami, G. H. (2007), Technology Management: Concepts and Approaches for Practical Application Technologies, Dar Al-Manhaj for Publishing, $1^{\text {ST }}$ Edition, Jordan. [In Arabic]

Ali, K N, \& Susan, G. R. A. (2014). The organizational climate in Al-Mustansiriya University from the viewpoint of Teaching staff faculty, Journal of the Faculty of Basic Education, 20 (84). [In Arabic]

Al-Assaf, M. S. (1995). Introduction to Research in Behavioral Sciences, Obeikan for Printing and Distribution, Riyadh. [In Arabic]

Al-Azzawi, M. A. (2013). The Impact of Dimensions of Intellectual Capital on the Creative Behavior of Workers, The Journal of Administration and Economics, 36 (94). [In Arabic]

Adjila, M., (2005). Creativity in the Algerian Economic establishment: A Study of the qualities, obstacles and motifs of Creativity, (Master Thesis, Saad Dahlab University, Blida. [In Arabic]

El-Sayed, M. M. (2002). The Impact of Empowerment and Career Enrichment on Workers' Loyalty in the Light of Reducing the Size of Employment, Scientific Journal of Economics and Commerce, Faculty of Commerce, 2. [In Arabic] 
المجلد 01 العدد 04 (2019) ص 160-178 ص

مجلـة بحوث الإدارة و الاقتصاد

Al-Salem, M. S. (1999). The Relationship between the Dimensions of Work Design and the Creative Behavior of Workers, Journal of Administrative Sciences Studies, 26 (1). [In Arabic]

Al-Usaimi, N. (2009). The organizational climate at Princess Noura bent Abd-Rahman University for Girls as seen by female faculty members, (Master Thesis, King Saud University, KSA). [In Arabic]

Hazar, R. A. (n.d), Al-Mutqan: The Illustrated Arabic Dictionary, Dar Al-Ratib University for Publishing, Edition.

Al-Ziyadin, Y. K. (2005). The Impact of Organizational Climate on Creative Behavior, (Master Thesis, Mu'tah University, Jordan). [In Arabic]

Parjanen, S. (2012). Experiencing creativity in the organization: From individual creativity to collective creativity. Interdisciplinary Journal of Information, Knowledge \& Management, 7.

The Impact of Organizational Climate on Creative Behavior: An Analytical Study on a Sample of Employees in the High Plateau Tannery in Djelfa

Mustapha Benaouda ${ }^{\star}$,Sabrina Hamiani ${ }^{2}$

Received: 15-11-2019 Accepted: 19-12-2019 Published: 24-12-2019

This study aimed to assess the prevailing organizational climate and the level of
creative behaviour in the tannery of the upper plateaus from the employees' point of view
and to determine whether there is a statistically significant effect of the organizational
climate on its creative behaviour. A questionnaire was designed and distributed to a random
sample to achieve the study's objectives $(36.45 \%$ of the size of the study population), where
the response rate was $(94.28 \%)$. The organizational climate and creative behaviour of the
institution under study were measured using a set of statistical tools such as arithmetic
averages, standard deviations, ratios, and averages, as well as correlation coefficient and
coefficient of determination. The results of the study showed that the employees' evaluation
of the organizational climate and creative behaviour is positive and that there is a
statistically significant effect at the level of significance ( $\alpha$ - 0.05$)$ of the organizational
climate in its dimensions on the creative behaviour of the employees in the institution under
study. One of the study's most important recommendations is to strengthen the current
working environment and increase its ability to embrace creative behaviour, increase
interest in the human element, and give appropriate incentives.
Keywords: Organizational Climate, Creative Behaviour, Tannery Upper Plateaus.
JEL Classification: M19.

1 Corresponding author: Ziane Achour University of Djelfa (Algeria), [ $₫$ benaoudamoustapha@gmail.com]

${ }^{2}$ Ziane Achour University of Djelfa (Algeria).

[ $₫$ sabrinahamiani@gmail.com] 